\title{
Cancer-Associated Fibroblasts Build and Secure the Tumor Microenvironment
}

\author{
Tianyi Liu', Linli Zhou', Danni Li' ${ }^{2}$, Thomas Andlis* and Yuhang Zhang ${ }^{1 *}$ \\ 'Division of Pharmaceutical Sciences, College of Pharmacy, University of Cincinnati, Cincinnati, OH, United States, ${ }^{2}$ College \\ of Chemistry and Chemical Engineering, Guangxi University for Nationalities, Nanning, China, ${ }^{3}$ Burnett School of Biomedical \\ Sciences, University of Central Florida, Orlando, FL, United States
}

\section{OPEN ACCESS}

Edited by:

Sandra Orsulic,

Cedars-Sinai Medical Center,

United States

Reviewed by:

Lasse Dahl Ejby Jensen,

Linköping University, Sweden

Ann E. Walts,

Cedars-Sinai Medical Center,

United States

*Correspondence:

Thomas And

thomas.andl@ucf.edu

Yuhang Zhang

yuhang.zhang@uc.edu;

zhang2y4@ucmail.uc.edu

Specialty section:

This article was submitted to

Molecular Medicine,

a section of the journal

Frontiers in Cell and Developmental

Biology

Received: 16 January 2019

Accepted: 05 April 2019

Published: 24 April 2019

Citation:

Liu T, Zhou L, Li D, Andl T and

Zhang Y (2019) Cancer-Associated

Fibroblasts Build and Secure

the Tumor Microenvironment.

Front. Cell Dev. Biol. 7:60.

doi: 10.3389/fcell.2019.00060
Tumor cells reside in a highly complex and heterogeneous tumor microenvironment (TME), which is composed of a myriad of genetically stable non-cancer cells, including fibroblasts, immune cells, endothelial cells, and epithelial cells, and a tumor-specific extracellular matrix (ECM). Cancer-associated fibroblasts (CAFs), as an abundant and active stromal cell population in the TME, function as the signaling center and remodeling machine to aid the creation of a desmoplastic tumor niche. Although there is no denial that the TME and CAFs may have anti-tumor effects as well, a great deal of findings reported in recent years have convincingly revealed the tumor-promoting effects of CAFs and CAF-derived ECM proteins, enzymes, chemical factors and other downstream effectors. While there is growing enthusiasm for the development of CAF-targeting therapies, a better understanding of the complexities of CAF-ECM and CAF-cancer cell interactions is necessary before novel therapeutic strategies targeting the malignant tumor "soil" can be successfully implemented in the clinic.

Keywords: cancer-associated fibroblast, tumor microenvironment, extracellular matrix, therapy, mechanoreciprocity

\section{INTRODUCTION}

In the last decades, despite considerable advances in the development of novel immunotherapies and targeted therapies, no significant improvements have been made in overall survival rates for patients with malignant solid tumors. One major reason for this lack of substantial improvement is the development of drug resistance in tumor cells, which usually reveals itself within a few months after patients are treated with anti-cancer drugs. An Achilles' heel of many current therapeutic approaches is that these therapies primarily target the fast-growing tumor "seeds" but largely ignore the fertilizing tumor "soil" - the tumor microenvironment (TME) (de Groot et al., 2017). The TME influences the penetration, distribution, and metabolism of therapeutic agents, and produces molecular factors and signals, which positively or negatively regulate how tumor cells grow, migrate and respond to therapeutic agents. As cancer-associated fibroblasts (CAFs) appear to be a major TME component in many tumors and are critical for shaping the "soil" within which the tumor cells thrive (LeBleu and Kalluri, 2018), they have become the prime target for the efforts to modify non-tumor cell behavior to suppress tumor growth. It is clear that the TME and CAFs are not always pro-tumorigenic due to the complexities of their interactions with tumor cells. However, in this review, we will mainly explore the tumor-promoting interactions between cancer cells and 
fibroblasts and how CAFs may be persuaded using novel therapeutic approaches to renounce their fealty to the tumor cells and even produce a tumor-suppressive "soil."

\section{STROMAL FIBROBLASTS, MYOFIBROBLASTS, AND CAFs}

Tumors are often referred to as "wounds that never heal" (Dvorak, 1986) because the stroma of a wound and a tumor share many similarities, such as fibroblast activation, increased extracellular matrix (ECM) protein production and intensive remodeling processes (Foster et al., 2018). Activated stroma is molecularly, biochemically and pathologically different from the normal stroma. In the stroma of normal human skin, fibrous proteins fill in the interstitial space between stromal fibroblasts while epithelial keratinocytes rest on the sheet-like basement membrane. Under normal physiological conditions, non-contractile fibroblasts are generally flat, spindle-shaped and recognized as quiescent and inert cells in the ECM (Valkenburg et al., 2018).

Myofibroblasts were first identified in the tissue wound repair process, during which fibroblasts or smooth muscle cells differentiate and gain a contractile phenotype (McAnulty, 2007). The major roles of myofibroblasts in wound healing are to contract the wounds and produce and organize the ECM (Darby et al., 2014). As the wound closes and heals, myofibroblasts become apoptotic and finally disappear as the scar is formed (Desmouliere et al., 1995). Myofibroblasts are different from normal fibroblasts in many aspects, including (1) ruffled membranes and a highly active endoplasmic reticulum (Baum and Duffy, 2011); (2) expression of alpha smooth muscle actin ( $\alpha$-SMA or ACTA2) and increased levels of vimentin (VIM) (Ronnov-Jessen and Petersen, 1993) and (3) formation of complex and organized stress fibers and fibronexus adhesion complexes (Rao et al., 2016). The bundles of microfilaments in myofibroblasts interact with the ECM proteins through fibronexus adhesion complexes, thereby allowing myofibroblasts to sense the tension in their surrounding microenvironment and maintain the cellular contractile force through the network of cytoskeletal proteins. As a feedback response, myofibroblasts increase matrix fibroplasia by producing ECM proteins, including collagen, elastin (ELN), fibronectin (FN1), tenascin (TNC), and remodeling enzymes, such as matrix metalloproteinases (MMPs).

Tumor growth recapitulates the basic wound healing program and shares many similarities, such as deposition and crosslinking of fibrin and FN1 and the recruitment of immune cells (Schafer and Werner, 2008). However, unlike a normal healing wound, which is restricted to a certain area and proceeds directionally through the steps of hemostasis, inflammation, proliferation, and maturation/remodeling, cancer cells distort the wound healing program and have the potential to migrate away or expand from the initiation site and invade adjacent tissues. CAFs are the fibroblasts found in the stroma of human cancers but differ from normal fibroblasts in their increased collagen and ECM protein production and up-regulated secretion of pro-tumor factors (Bauer et al., 2010; Xing et al., 2010; Pidsley et al., 2018). There are several important sources from which CAFs could be derived, including: (i) recruitment and activation of resident fibroblasts (Fukino et al., 2004); (ii) epithelial-mesenchymal transition (EMT) of resident epithelial cells (Petersen et al., 2001); (iii) endothelial to mesenchymal transition (EndMT) of resident endothelial cells (Zeisberg et al., 2007a,b) and (iv) differentiation of bone marrow mesenchymal cells (Quante et al., 2011). In a sense, CAFs or at least a subset of CAFs are wound-like myofibroblasts that mediate a deranged chronic wound healing program in tumors. For example, a large part of CAFs share similar features as $\alpha$-SMA-positive $(\alpha$-SMA + ) myofibroblasts (Shiga et al., 2015). In addition, other than myofibroblastic CAFs, subpopulations of CAFs without $\alpha$-SMA expression have also been reported, e.g., in pancreatic cancer (Ohlund et al., 2017).

\section{HETEROGENEITY OF STROMAL FIBROBLASTS, MYOFIBROBLASTS, AND CAFs}

Understanding the state, complexity and heterogeneity of normal fibroblasts may shed light on the origins of CAFs, how they form and how their transdifferentiation may be regulated in the early stages of tumorigenesis and at the tumor front. Two major populations of fibroblasts in the human dermis are papillary and reticular fibroblasts, which possess distinct morphology, molecular expression, and cellular functions (Harper and Grove, 1979). Janson et al. (2012) performed gene expression analysis on cultured papillary and reticular fibroblasts and identified 116 differentially expressed genes. However, except for matrix Gla protein (MGP), which is almost exclusively expressed in the reticular dermis, they did not discover any in vivo markers to separate the two fibroblast populations. Korosec et al. (2019) performed lineage identity and location studies of human dermis using two markers, fibroblast activation protein (FAP) and THY1 (Cluster of Differentiation 90 or CD90). They found that papillary fibroblasts are $\mathrm{FAP}^{+}$; $\mathrm{THY}^{-}$, whereas $\mathrm{FAP}^{-}$; $\mathrm{THY}^{+}{ }^{+}$fibroblasts are mainly of the reticular lineage. Their data showed papillary and reticular fibroblasts are not completely separated according to their spatial location.

However, recent studies have suggested that there exist more functionally distinct fibroblast subpopulations within the human dermis. A single-cell RNA sequencing (scRNA-seq) study by Philippeos et al. (2018) showed that there are five distinct fibroblast populations in adult human skin, which can be separated based on the expression of cell surface markers, including THY1, CD39, CD26 (DPP4), and regulator of G protein signaling 5 (RGS5), and are not spatially segregated. Tabib et al. (2018) performed single-cell transcriptomal analysis of cells obtained from whole skin without pre-purifying fibroblast populations. They identified two major fibroblast populations based on the expression of SFRP2/DPP4 and FMO1/LSP1 markers and five minor cell populations using CRABP1, COL11A1, PRG4, ANGPTL7, and SFRP4. In addition, there are several subpopulations in each major fibroblast population. These scRNA-seq data showed a complex and heterogeneous 
picture of fibroblast composition and functionality in the human dermis, which is simply beyond our original understanding of skin fibroblasts. Nevertheless, it remains to be understood how these subpopulations of fibroblasts react to either wounding or the tumorigenic process and evolve into myofibroblasts or CAFs.

Local fibroblasts are the most common origin of myofibroblasts (Hinz et al., 2007). However, several other cell types are able to differentiate into myofibroblasts, including smooth muscle cells or pericytes (Hinz et al., 2007). Fibrocytes, for example, can differentiate into myofibroblasts in skin, liver and lung tissues (Mori et al., 2005; Iwaisako et al., 2012; Ashley et al., 2017). In the liver, hepatic stellate cells are the source of myofibroblasts in liver fibrosis (Wells and Schwabe, 2015). Because of the nature of its diverse origins, myofibroblasts appear to be a heterogeneous group as well. $\alpha$-SMA is the most commonly used marker to identify myofibroblasts (McAnulty, 2007). In addition, extra domain A fibronectin (EDA-FN), periostin (POSTN) and prolyl-4-hydroxylase (P4HB) have also been suggested as potential markers for myofibroblasts (MooreMorris et al., 2014; Ngo et al., 2014; Kanisicak et al., 2016). A recent study proposed that amine oxidase, copper containing 3 (AOC3) and homeobox protein NKX2-3 are two biomarkers of pericryptal myofibroblasts in the colon and rectum (Hsia et al., 2016). Furthermore, markers that stain stromal fibroblasts can also be used to stain myofibroblasts, such as platelet derived growth factor receptor alpha (PDGFRA), THY1, and VIM, although they are not specific for myofibroblasts (Matthijs Blankesteijn, 2015).

Just like normal fibroblasts, CAFs appear to be a heterogeneous group of cells with different origins and different functions. This similarity was manifested by a study reported by Lambrechts et al. (2018). By performing scRNA-seq of 52,698 stromal cells isolated from human lung tumors and comparing with matching non-malignant lung samples, the authors identified five distinct types of fibroblasts in lung tumors, which all express their own unique set of collagens and ECM proteins that are different from non-malignant fibroblasts. Using a three-dimensional (3D) co-culture platform, Ohlund et al. (2017) identified two distinct populations of myofibroblasts and inflammatory fibroblasts in pancreatic ductal adenocarcinoma (PDA). More recently, the obscurity in CAF characterization has been further addressed by efforts to determine the exact composition of human tumor tissues using scRNA-seq. scRNA-seq data derived from head and neck squamous cell carcinoma (HNSCC) suggested that tumor myofibroblasts and CAFs may represent distinct fibroblast subpopulations (Puram et al., 2017). Overall, the authors were able to detect, in addition to normal fibroblasts and myofibroblast-like cells, two subsets of CAFs depending on the expression of FAP, THY1, connective tissue growth factor (CTGF) and podoplanin (PDPN). In their study, tumor myofibroblasts were identified based on the expression of $\alpha$-SMA, melanoma cell adhesion molecule (MCAM), myosin light chain kinase (MYLK), and myosin light chain 9 (MYL9). Interestingly, scRNA-seq of colorectal cancer samples also revealed at least three fibroblast populations (Li et al., 2017). One population can be described as normal fibroblasts, the second one as myofibroblasts, which are positive for $\alpha$-SMA, transgelin (TAGLN) and PDGFA, and the third one as a CAF population that is characterized by MMP2, decorin (DCN) and collagen type I alpha 2 (COL1A2). The authors determined that a key signaling pathway emanating from CAFs/myofibroblasts is transforming growth factor beta (TGF- $\beta$ )/INHBA signaling, ascertaining that CAFs are not just ECM-producing factories. The scRNA-seq results of fibroblast populations are in good accordance with attempts to characterize CAFs using fluorescence activated cell sorting (FACS) (Costa et al., 2018). Such efforts in human breast cancer using six CAF markers, including FAP, integrin beta 1 (ITGB1), $\alpha$-SMA, FSP1, platelet derived growth factor receptor beta (PDGFRB), and caveolin-1 (CAV1), allowed the authors to identify four distinct CAF populations, of which some were preferentially present in subsets of breast cancers. Two of the CAF populations expressed $\alpha$-SMA and probably represent myofibroblast-like cells. However, a comparison of the two $\alpha$-SMA+ populations revealed that one was similar to pericytes and expressed MCAM and a gene signature related to the regulation of actin cytoskeleton and muscle contraction. The second $\alpha$-SMA+ population exhibited an immune-regulatory gene signature. These CAFs can function as immune-suppressors and regulators of T lymphocytes and create an immunosuppressive environment through a multi-step mechanism (Costa et al., 2018).

scRNA-seq studies of CAFs have suggested that CAF subtypes could be attributed to their origin in spatial subgroups of normal fibroblasts (Philippeos et al., 2018; Tabib et al., 2018). However, Biffi et al. (2019) reported that tumor-secreted TGF- $\beta$ / and IL1 can promote CAF heterogeneity. Subsets of CAFs can function to either support or suppress tumor cells. For example, it was reported that cancer cells undergo the EMT process and acquire invasive phenotypes through the activation of the TGF- $\beta$-SMAD signaling pathway induced by CAFs (Bellomo et al., 2016). In addition, by producing pro-angiogenic factors, such as fibroblast growth factor 2 (FGF2) and VEGFA (De Palma et al., 2017), CAFs regulate angiogenesis in the stroma, thereby providing essential nutrients for highly proliferative tumor cells. CAFs can also assist tumor cells in overcoming immune surveillance by recruiting immunosuppressive cells, such as M2 macrophages and myeloid-derived suppressor cells (MDSC) (Flavell et al., 2010; Yang et al., 2016). However, it was reported that ablation of subsets of $\alpha$-SMA + CAFs in PDA could result in a more aggressive cancer phenotype and reduced animal survival (Ozdemir et al., 2014). In summary, the heterogeneity of CAFs reflects the diversity and complexity of the TME, and more careful research is needed to fully comprehend the interactions among CAFs, tumor cells and the ECM.

\section{CAF-DERIVED ECM PROTEINS}

The tumor ECM is composed of a complex mixture of macromolecules, including fibrous proteins (collagen, ELN), proteoglycans (heparan sulfate, chondroitin sulfate), glycosaminoglycans (hyaluronic acid), and glycoproteins (FN1, laminins, TNC) (Botti et al., 2013). ECM proteins are not just bystanders of the tumorigenic process. Instead, they provide structural signals and support for tumor cells to grow and 


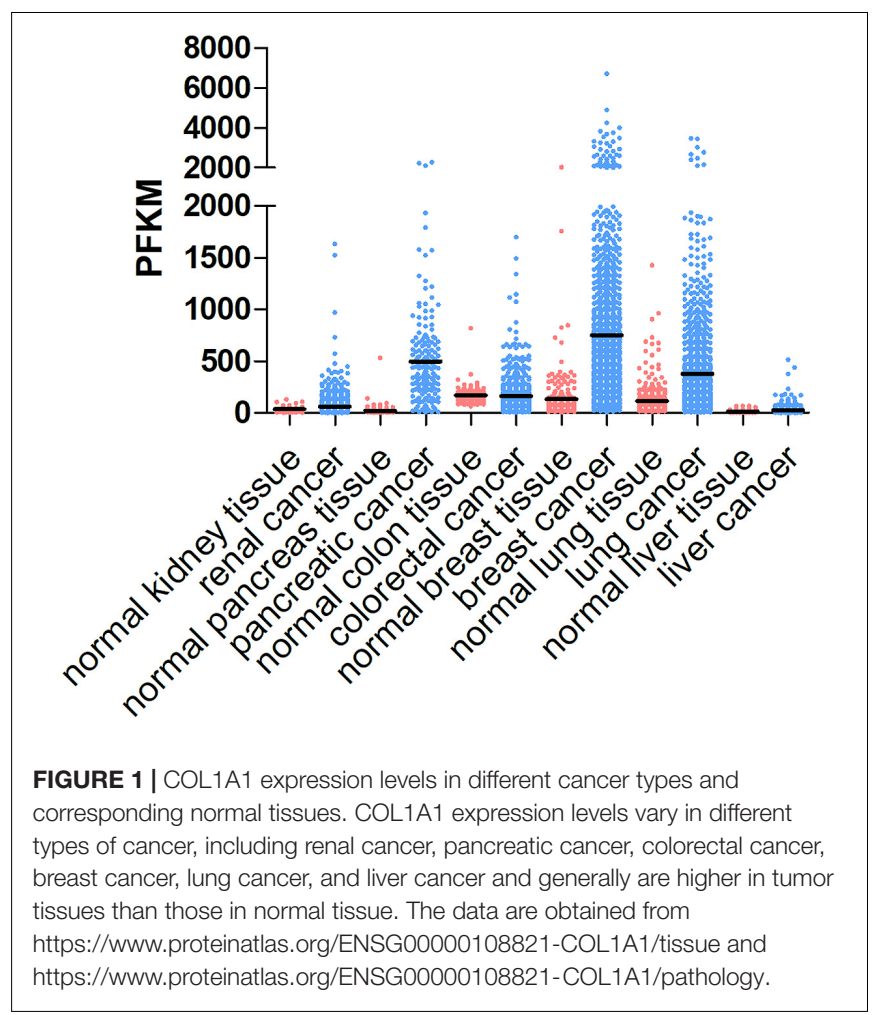

migrate. Although many other stromal cell types and tumor cells can also produce ECM proteins, CAFs appear to be the major player in the stroma that synthesizes, secrets, assembles and modifies the ECM composition and organization (Faouzi et al., 1999; Yoshimura et al., 2015; Erdogan et al., 2017). For example, elevated collagen production and crosslinking have been coupled with increased tumor stiffness and progression. It was estimated that fetal rat fibroblasts synthesize about 40 molecules of procollagen/cell per second (McAnulty et al., 1991). Many cancers are characterized by elevated levels of collagen production, e.g., COL1A1 (Figure 1). Faouzi et al. (1999) reported that myofibroblasts are the primary source of collagen (types I, IV, V and VI) in the stroma of human hepatocellular carcinoma. In addition, CAF-derived laminin was shown to induce cervical cancer cell migration via the interaction with integrin $\alpha 6 \beta 4$ (Fullar et al., 2015). In an in vitro ovarian cancer spheroid model, CAF-secreted versican promoted cancer invasion in a TGF- $\beta$-dependent manner (Yeung et al., 2013).

FN1 was first found to be overexpressed in human solid tumor specimens in 1981 (Stenman and Vaheri, 1981). Although tumor cells produce FN1 themselves, stromal cells, such as CAFs, are indispensable for bulk FN1 assembly (Attieh et al., 2017; Erdogan et al., 2017). Like collagen, the pro-tumorigenic role of FN1 is also well-acknowledged. In 1998, Menzin et al. (1998) proposed that FN1 may play an important role in regulating the invasive phenotype and poor patient prognosis in ovarian cancer. FN1 was also documented to promote cell cohesion, basement membrane invasion and tumor growth in glioblastoma (GBM). Depletion of FN1 in GBM cells resulted in weaker cell-cell contact and less collective migration in an in vitro spheroid model, highlighting the role of $\mathrm{FN1}$ as a "biological glue" (Serres et al., 2014). The role of FN1 in cell cohesion has also been observed in fibroblast spheroids. FN1-depleted fibroblasts failed to form compact spheroids in vitro. Furthermore, the blockade of FN1-integrin interactions impeded fibroblast activation (Salmenpera et al., 2008).

Tenascin is another highly expressed ECM glycoprotein in the tumor stroma, such as the stroma of canine mammary carcinoma, pancreatic cancer and prostate cancer, and is associated with poor patient prognosis (Yoshimura et al., 2015; Cai et al., 2017; $\mathrm{Ni}$ et al., 2017). Mouse embryonic fibroblasts lacking TNC have robust overexpression of tissue plasminogen activator (tPA) and increased capacity to digest fibrin in situ (Brellier et al., 2011). Furthermore, they discovered that there was a correlation between in vivo TNC expression and fibrin accumulation in head and neck squamous cell carcinomas (SCC) and lung carcinomas, further confirming that TNC functions as a regulator of the fibrinolytic system.

\section{CAF-DERIVED ECM ENZYMES}

Tumor progression and metastasis require a distinct ECM biomechanical architecture, for which CAFs not only produce and secrete ECM proteins and also actively participate in the ECM proteolysis, crosslinking and assembly processes. In such a rigid and highly crosslinked tumor stroma, drug penetration is one potential reason for tumor cells to escape therapy. In addition, CAF-mediated ECM remodeling is a highly responsive process of receiving, processing and responding to the cellular, molecular and mechanical signals in the TME. The lysyl oxidase (LOX) family and MMPs represent two major types of remodeling enzymes produced by CAFs. As a highly adaptive and mechanically responsive stromal cell type, CAFs sense and respond to the ECM stiffness in a LOX/MMP-dependent manner and further fine-tune the CAF-ECM interactions.

The LOX family oxidases include five members: LOX and lysyl oxidase like (LOXL) 1, 2, 3, and 4 (Wang et al., 2016). They share similar structures and catalyze the crosslinking of collagen and ELN by oxidation, contributing to increased stiffness of the tumor stroma. In tissue fibrosis, it was demonstrated that fibroblast-derived LOX could be induced by different soluble factors, such as insulin-like growth factor-binding protein 5 (IGFBP5) (Nguyen et al., 2018) and POSTN (Kumar et al., 2018), and by the transcription factor hypoxia inducible factor 2 alpha (HIF2A) (Hikage et al., 2019). Elevated levels of LOX family oxidases are often observed in cancers and play a prominent role in cancer progression. Gene expression analysis of mouse mammary tumors revealed that activated fibroblasts are the major producers of LOX family oxidases (Pickup et al., 2013). When colon cancer patient-derived CAFs and normal fibroblasts were compared by proteomic analysis, LOXL2 was found to be overexpressed in CAFs and was identified as a predictive prognostic factor in stage II colon cancer patients (Torres et al., 2015). Similarly, LOXL2 expression in gastric CAFs was also demonstrated to be positively correlated with the invasive ability of gastric cancer cells (Kasashima et al., 2014). 
TABLE 1 | Expression of MMP2 and MMP9 is correlated with cancer progression and metastasis.

\begin{tabular}{|c|c|c|c|}
\hline MMP2 & References & MMP9 & References \\
\hline Basal-cell carcinoma & Gozdzialska et al., 2016 & Basal-cell carcinoma & Gozdzialska et al., 2016 \\
\hline Brain cancer & Wang M. et al., 2003; Tabouret et al., 2014 & Brain cancer & Wang M. et al., 2003; Li et al., 2016 \\
\hline Breast cancer & $\begin{array}{l}\text { Yari et al., 2014; Chen Y. et al., 2015; Ramos } \\
\text { et al., 2016; Tabouret et al., } 2016\end{array}$ & Breast cancer & Wu et al., 2014; Yousef et al., 2014 \\
\hline Colorectal cancer & Groblewska et al., 2014 & Gastric cancer & Wang et al., 2014; Chen S.Z. et al., 2015 \\
\hline Endometrial adenocarcinoma & Li et al., 2014 & Liver cancer & Sun et al., 2014 \\
\hline Gastric cancer & Wang et al., 2014 & Lung cancer & $\begin{array}{l}\text { Lee et al., 2015; Zhang et al., 2015; Gong } \\
\text { et al., 2016; Yu et al., } 2016\end{array}$ \\
\hline Lingual and gingival cancers & Nishio et al., 2016 & Pancreatic cancer & Jakubowska et al., 2016 \\
\hline Lung cancer & Zhang et al., 2015 & Pituitary adenoma & Liu et al., 2016 \\
\hline Melanoma & Kamyab-Hesari et al., 2014 & Prostate cancer & Oguic et al., 2014 \\
\hline Osteosarcoma & Zhang and Zhang, 2015 & Squamous cell carcinoma & Stanciu et al., 2016 \\
\hline Ovarian cancer & Fu et al., 2015 & & \\
\hline
\end{tabular}

In breast cancer, LOXL2 inhibition showed anti-tumor effects in reducing tumor size and angiogenesis. Furthermore, a combination of LOX and LOXL2 inhibitors resulted in even smaller and less metastatic tumors (Chang et al., 2017). Interestingly, in mice bearing aggressive breast cancer, anti-LOXL2 monoclonal antibody AB0023 exhibited potent inhibitory effects in activated fibroblast as suggested by an $88 \%$ reduction of $\alpha$-SMA + cells by immunohistochemistry (IHC) after AB0023 treatment (Barry-Hamilton et al., 2010). The inhibitory effect was also shown to be closely associated with the reduction in cross-linked collagenous ECM matrix. Recently, an in vitro study using siRNA adenovirus vector to silence LOXL2 expression in mouse lung fibroblast also showed that the proliferation of lung fibroblasts was significantly decreased via the TGF- $\beta /$ Smad signaling pathway (Wen et al., 2018). All these findings highlighted the role of CAF-derived LOX family oxidases in regulating tumor migration and invasion and potential beneficial outcomes of targeting CAF-synthesized LOX family oxidases.

The ability of cancer cells to digest surrounding ECM and localize to distal sites has long been attributed to MMPs, which are zinc-containing endopeptidases. MMPs play pivotal roles in creating the paths for tumor cells to leave the primary tumor niche and wade through the stiff matrix. There are 24 MMPs in mammals (Vandenbroucke and Libert, 2014), of which MMP2 and MMP9 are found to be overexpressed in many cancer types and promote tumor progression and metastasis (Table 1). CAFs were shown to be the major producer of MMP2 in mouse lung tumors as indicated by IHC staining results showing MMP2 primarily localizes to fibroblasts (Bates et al., 2015). Using the online database proteinatlas.org, we summarized the correlation between 13 MMPs and patient prognosis status in nine human cancers in Table 2 based on the RNA-Seq data. Four MMPs (MMP10, MMP15, MMP24, MMP25) are shown to be favorable to patient prognosis as their expression levels are positively correlated with patient survival. However, the expression levels of eight MMPs (MMP1, MMP3, MMP7, MMP11, MMP12, MMP14, MMP19, and MMP28) are shown to be negatively correlated with patient survival. Interestingly, MMP9 seemed to have context-dependent roles in different cancer types. In conclusion, the roles of different MMPs in the TME need to be carefully examined based on cancer types and stages, and this should also be one major consideration when designing, dosing and scheduling MMP-targeting drugs for cancer patients (Iyer et al., 2012).

\section{CAF-ECM INTERACTIONS}

The interactions between CAFs and the ECM influence the stiffness of the tumor stroma and can be described using the term "mechanoreciprocity" (van Helvert et al., 2018), which consists of both "outside-in" and "inside-out" signaling modes (Shattil et al., 2010). The "outside-in" signaling mode is a well-established mechanism, by which ECM proteins can function as ligands and bind to integrin receptors on the cell membrane (Table 3). Integrins are transmembrane receptors composed of a heterodimer of $\alpha$ and $\beta$ subunits. As shown in Figure 2, when the cells encounter a rigid ECM, the integrin molecules become dimerized to trigger the focal adhesion cascade and the activation of downstream signaling, including tyrosine protein kinase SRC and focal adhesion kinase FAK1, thereby converting external mechanical signals into cellular and biochemical signals inside the cells (Barczyk et al., 2010; Tucker and Chiquet-Ehrismann, 2015; Benito-Jardon et al., 2017). Integrin $\alpha 11 \beta 1$ is a stromal cell-specific receptor for collagen and also known as an important regulator for fibroblast activation (Carracedo et al., 2010). Zhu et al. (2007) showed that the growth of the tumors formed by non-small-cell lung carcinoma (NSCLC) cell lines, A549, NCI-H460, and NCI-H520 mixed with integrin a11-deficient fibroblasts were significantly impeded as compared with the tumors derived from the mixture of either tumor cell line and wild-type fibroblasts. In this case, fibroblasts, originally good "listeners" and "responders" to the mechanical cues, lost their active ECM remodeling ability after the fibroblast-ECM interaction was blocked. In another example, cardiac fibroblasts cultured on a stiff matrix expressed increased amounts of LOX, further crosslinked collagen fibers and stiffened the ECM. To the contrary, the inhibition of the binding between $\alpha 2 \beta 1$ integrin and collagen I ablated this effect and downregulated LOX expression (Gao et al., 2016). In the "outside-in" signaling mode, the mechanical cues can also activate other signaling pathways in fibroblasts, such as the mitogen-activated protein kinase (MAPK) 
TABLE 2 | Correlations between MMP/LOX expression and the 5-year survival rates of cancer patients**

\begin{tabular}{|c|c|c|c|c|c|c|}
\hline \multirow[t]{2}{*}{ MMP/LOX } & \multirow[t]{2}{*}{ Prognosis* } & \multirow[t]{2}{*}{ Cancer type } & \multicolumn{2}{|c|}{ 5-year survival } & \multirow[b]{2}{*}{ Sample size } & \multirow[b]{2}{*}{$p$-value } \\
\hline & & & High expression & Low expression & & \\
\hline \multirow[t]{3}{*}{ MMP1 } & Unfavorable & Renal cancer & $60 \%$ & $82 \%$ & 877 & $9.90 \mathrm{E}-10$ \\
\hline & Unfavorable & Liver cancer & $36 \%$ & $50 \%$ & 365 & 0.0000042 \\
\hline & Unfavorable & Cervical cancer & $59 \%$ & $74 \%$ & 291 & 0.00047 \\
\hline \multirow[t]{2}{*}{ MMP3 } & Unfavorable & Pancreatic cancer & $5 \%$ & $34 \%$ & 176 & 0.00041 \\
\hline & Unfavorable & Cervical cancer & $45 \%$ & $71 \%$ & 291 & 0.00097 \\
\hline \multirow[t]{2}{*}{ MMP7 } & Unfavorable & Liver cancer & $38 \%$ & $60 \%$ & 365 & 0.00025 \\
\hline & Unfavorable & Lung cancer & $34 \%$ & $50 \%$ & 994 & 0.00034 \\
\hline \multirow[t]{3}{*}{ MMP9 } & Unfavorable & Renal cancer & $64 \%$ & $78 \%$ & 877 & 0.000041 \\
\hline & Favorable & Endometrial cancer & $81 \%$ & $60 \%$ & 541 & 0.00025 \\
\hline & Unfavorable & Liver cancer & $37 \%$ & $64 \%$ & 365 & 0.00072 \\
\hline MMP10 & Favorable & Urothelial cancer & $48 \%$ & $27 \%$ & 406 & 0.00071 \\
\hline MMP11 & Unfavorable & Renal cancer & $65 \%$ & $81 \%$ & 877 & 0.00026 \\
\hline MMP12 & Unfavorable & Liver cancer & $33 \%$ & $51 \%$ & 365 & 0.00014 \\
\hline \multirow[t]{2}{*}{ MMP14 } & Unfavorable & Renal cancer & $58 \%$ & $73 \%$ & 873 & 0.00013 \\
\hline & Unfavorable & Ovarian cancer & $20 \%$ & $35 \%$ & 373 & 0.00095 \\
\hline \multirow[t]{2}{*}{ MMP15 } & Favorable & Renal cancer & $86 \%$ & $65 \%$ & 877 & 8.50E-08 \\
\hline & Favorable & Urothelial cancer & $49 \%$ & $30 \%$ & 406 & 0.00031 \\
\hline MMP19 & Unfavorable & Renal cancer & $62 \%$ & $81 \%$ & 877 & 8.60E-09 \\
\hline MMP24 & Favorable & Renal cancer & $74 \%$ & $51 \%$ & 877 & $8.20 \mathrm{E}-11$ \\
\hline MMP25 & Favorable & Head and neck cancer & $51 \%$ & $29 \%$ & 499 & 0.000011 \\
\hline MMP28 & Unfavorable & Pancreatic cancer & $16 \%$ & $40 \%$ & 176 & 0.0000063 \\
\hline \multirow[t]{3}{*}{ LOX } & Unfavorable & Renal cancer & $64 \%$ & $87 \%$ & 877 & $3.90 \mathrm{E}-08$ \\
\hline & Unfavorable & Urothelial cancer & $25 \%$ & $51 \%$ & 406 & 0.00033 \\
\hline & Unfavorable & Liver cancer & $36 \%$ & $52 \%$ & 365 & 0.00074 \\
\hline LOXL1 & Unfavorable & Glioma & 0 & $10 \%$ & 153 & 0.00013 \\
\hline \multirow[t]{5}{*}{ LOXL2 } & Unfavorable & Lung cancer & $31 \%$ & $57 \%$ & 994 & $1.50 \mathrm{E}-07$ \\
\hline & Unfavorable & Renal cancer & $54 \%$ & $72 \%$ & 877 & $2.90 \mathrm{E}-07$ \\
\hline & Unfavorable & Cervical cancer & $52 \%$ & $82 \%$ & 291 & 0.0000098 \\
\hline & Unfavorable & Glioma & 0 & $10 \%$ & 153 & 0.00018 \\
\hline & Unfavorable & Pancreatic cancer & $6 \%$ & $43 \%$ & 176 & 0.00091 \\
\hline LOXL3 & Unfavorable & Renal cancer & $61 \%$ & $77 \%$ & 877 & 8E-08 \\
\hline \multirow[t]{2}{*}{ LOXL4 } & Unfavorable & Glioma & $2 \%$ & $16 \%$ & 153 & 0.00054 \\
\hline & Unfavorable & Ovarian cancer & $23 \%$ & $39 \%$ & 373 & 0.00096 \\
\hline
\end{tabular}

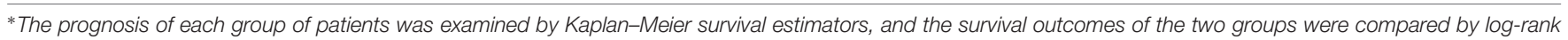
tests.

** Data available from:

MMP1: https://www.proteinatlas.org/ENSG00000196611-MMP1/pathology

MMP3: https://www.proteinatlas.org/ENSG00000149968-MMP3/pathology

MMP7: https://www.proteinatlas.org/ENSG00000137673-MMP7/pathology

MMP9: https://www.proteinatlas.org/ENSG00000100985-MMP9/pathology

MMP10: https://www.proteinatlas.org/ENSG00000166670-MMP10/pathology

MMP11: https://www.proteinatlas.org/ENSG00000099953-MMP11/pathology MMP12: https://www.proteinatlas.org/ENSG00000262406-MMP12/pathology MMP14: https://www.proteinatlas.org/ENSG00000157227-MMP14/pathology MMP15: https://www.proteinatlas.org/ENSG00000102996-MMP15/pathology MMP19: https://www.proteinatlas.org/ENSG00000123342-MMP19/pathology MMP24: https://www.proteinatlas.org/ENSG00000125966-MMP24/pathology MMP25: https://www.proteinatlas.org/ENSG00000008516-MMP25/pathology MMP28: https://www.proteinatlas.org/ENSG00000271447-MMP28/pathology LOX: https://www.proteinatlas.org/ENSG00000113083-LOX/pathology LOXL1: https://www.proteinatlas.org/ENSG00000129038-LOXL1/pathology LOXL2: https://www.proteinatlas.org/ENSG00000134013-LOXL2/pathology LOXL3: https://www.proteinatlas.org/ENSG00000115318-LOXL3/pathology LOXL4: https://www.proteinatlas.org/ENSG00000138131-LOXL4/pathology 
TABLE 3 | Integrins and their ECM partners.

\begin{tabular}{lll}
\hline ECM Protein & Interacting Integrins & References \\
\hline Collagen & $\alpha 1 \beta 1, \alpha 2 \beta 1, \alpha 10 \beta 1, \alpha 11 \beta 1$ & Leitinger, 2011 \\
Fibronectin & $\alpha 4 \beta 1, \alpha 5 \beta 1, \alpha 8 \beta 1, \alpha$ llb $\beta 1$, & Pankov and Yamada, 2002; \\
& $\alpha \vee \beta 3, \alpha \vee \beta 6, \alpha \vee \beta 8$ & Danen et al., 2005 \\
Tenascin-C & $\alpha 9 \beta 1, \alpha 8 \beta 1, \alpha \vee \beta 1, \alpha \vee \beta 6$ & Tucker and Chiquet-Ehrismann, 2015 \\
Laminin & $\alpha 3 \beta 1, \alpha 6 \beta 1, \alpha 7 \beta 1, \alpha 6 \beta 4$ & Belkin and Stepp, 2000; Yamada and \\
& & Sekiguchi, 2015
\end{tabular}

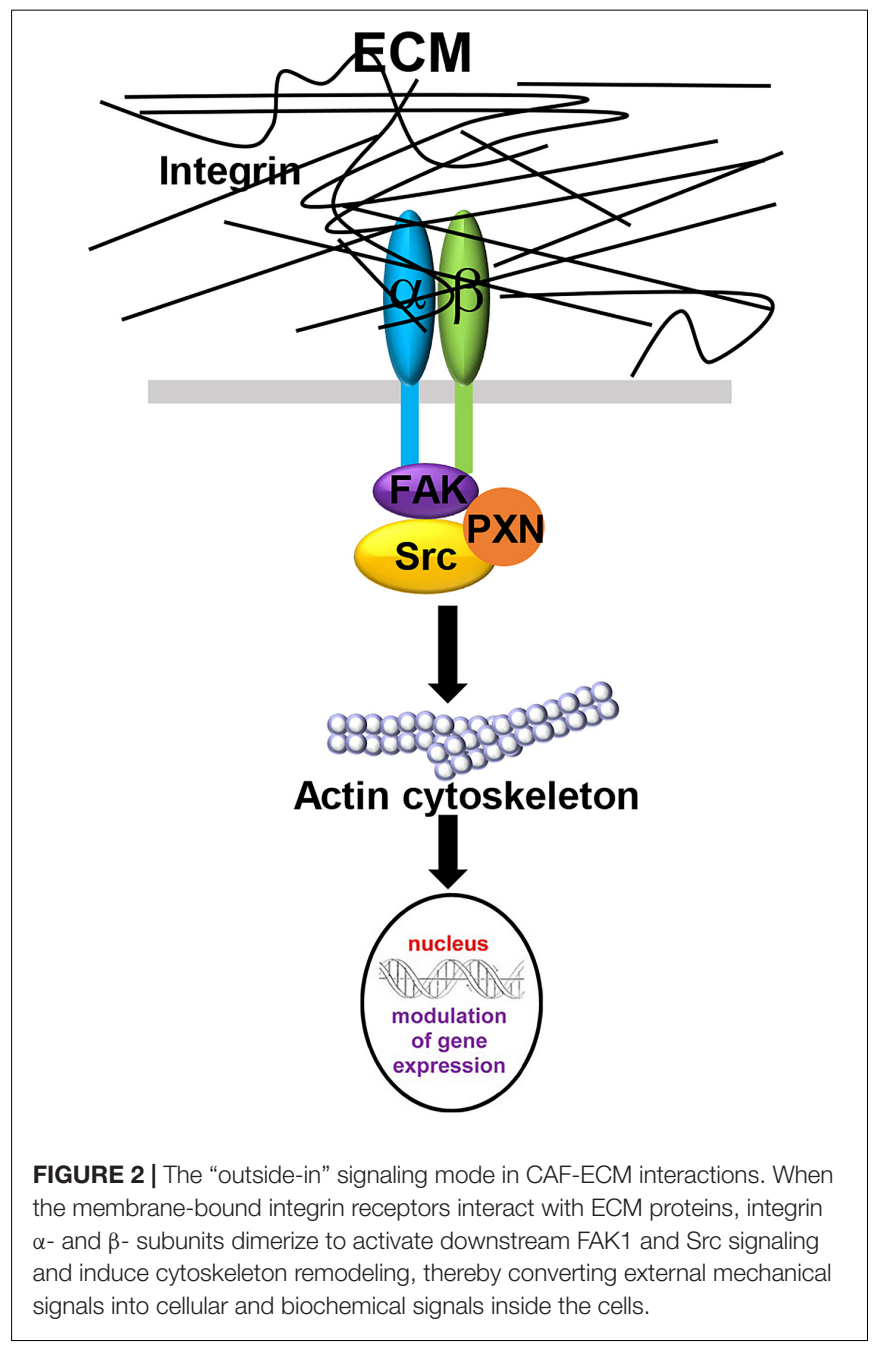

pathway (Wang J. et al., 2003; Paszek et al., 2005). In addition, it was reported that increased ECM stiffness could also activate the SRC-YAP-MYL9/MYL2 axis in CAFs to maintain the CAF phenotype. A positive feedback loop is established between CAF function and ECM stiffness, leading the stiff tumor stroma to become even stiffer and more favorable for cancer cell invasion (Calvo et al., 2013).

The "inside-out" signaling mode refers to the regulation of integrin-ECM interactions by intracellular signals. CAFs respond to tissue tension and exert their ECM remodeling and assembly abilities to further increase the stiffness of the stroma. The "inside-out" signaling mode is normally triggered by the binding of intracellular molecules, such as talin or kindlin, to the tails of integrins, leading to an increased affinity for extracellular ligands and enhanced ECM signaling (Shattil et al., 2010). For example, CAFs exert contractile forces and mediate extracellular FN1 assembly mainly via integrin $\alpha \mathrm{v} \beta 3$, leading to increased FN1 fibrillogenesis and ultimately contributing to tumor invasion (Attieh et al., 2017). Similarly, FN1 production and assembly were also observed in CAFs in prostate cancer. Erdogan et al. (2017) reported that CAFs produce an FN1-rich ECM with anisotropic fiber orientation as compared with normal fibroblasts and regulate cancer cell migration. In their study, CAFs remodel the FN1-rich ECM via the non-muscle myosin II (NMII)- $\alpha 5 \beta 1$ integrin axis.

\section{DIRECT CAF-CANCER CELL CONTACT}

Cancer-associated fibroblast-dependent tumor-promoting roles have long been attributed to the CAF secretome, but there is no denying that direct cell-cell contact also plays an important role in CAF-mediated cancer cell migration and invasion. Labernadie et al. (2017) discovered a heterotypic E-cadherin/N-cadherin adhesion complex between CAF and SCC cells. As shown in Figure 3, CAFs migrate through the ECM via integrin-mediated

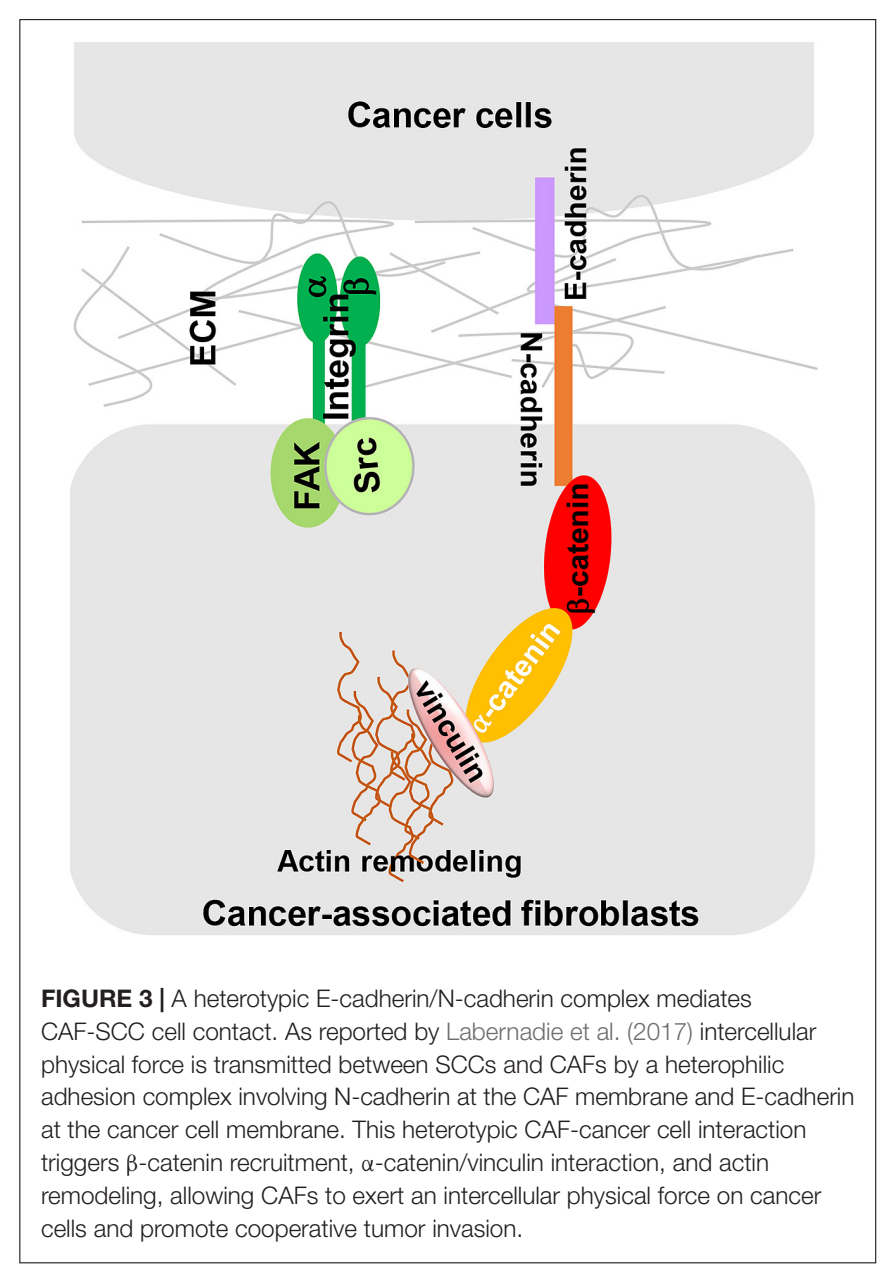


cytoskeleton remodeling and actomyosin reassembly while dragging tumor cells through CAF-cancer cell interaction via this heterotypic cadherin complex. The intercellular physical force between cancer cells and CAFs promote cooperative tumor invasion by triggering $\beta$-catenin recruitment, $\beta$-catenin/vinculin interaction and actin remodeling in both cell types.

In NSCLC, CAFs could potently enhance the motility of NSCLC cells through direct cell-cell contact via the hedgehog signaling pathway. Two co-culture systems (direct co-culture and indirect co-culture) were utilized to differentiate whether the motility-promoting effect is mediated by paracrine factors or cell-cell contact. Interestingly, increased tumor cell migration was only shown in a direct co-culture system, suggesting that CAF-promoted NSCLC cell migration is mediated by direct cell-cell contact (Choe et al., 2013). PDPN is a transmembrane glycoprotein that is known to be correlated with poor patient prognosis in lung adenocarcinoma (Ito et al., 2012). In an in vitro $3 \mathrm{D}$ collagen invasion model, PDPN-positive (PDPN+) CAFs accelerated lung tumor cell invasion into the collagen matrix. Ablation of PDPN reduced the invasive behavior of both CAFs and lung tumor cells. Because PDPN+ CAFs were observed to display high RHOA activity, RHO Kinase (ROCK) inhibitors were used to treat CAFs before co-culturing with lung tumor cells. ROCK inhibition suppressed PDPN-induced tumor cell migration, highlighting the role of the RHOA/ROCK axis in CAF-dependent tumor invasion (Neri et al., 2015).

\section{INDIRECT CAF-CANCER CELL INTERACTIONS}

Paracrine signaling between CAFs and cancer cells represents another well-studied mode of interaction between the two cell types that shapes the TME and promotes tumor growth. Hepatocyte growth factor (HGF) is a paracrine growth factor known to contribute to cancer progression. In cancer cells, HGF activates downstream RAS/MAPK and PI3K signaling pathways by binding to its receptor MET (Organ and Tsao, 2011). Cytokine antibody arrays suggested that HGF was the most significantly upregulated secreted factor in CAFs in breast cancer when compared to normal fibroblasts, which is positively correlated to their pro-tumorigenic ability to promote breast tumorigenesis in mice (Tyan et al., 2011). Similarly, the tumorpromoting functions of CAF-derived HGF were also observed in gastric cancer. By ablating HGF expression in vivo, CAFs failed to promote tumor growth in nude mice (Wu et al., 2013). Interestingly, CAF-derived HGF is also sufficient to induce RAF inhibitor resistance via the binding of its receptor MET and reactivation of the MAPK and $\mathrm{PI} 3 \mathrm{~K} / \mathrm{AKT}$ signaling pathways in melanoma cells. $50 \mathrm{nM}$ of recombinant HGF induced strong drug resistance to a BRAF inhibitor, vemurafenib, in several melanoma cell lines (Straussman et al., 2012).

CXCL12, also known as stromal cell-derived factor 1 (SDF1), is an important regulator in cancer initiation, angiogenesis, and metastasis (Orimo et al., 2005; Sugihara et al., 2015; Teng et al., 2016). In addition, CXCL12 was shown to induce angiogenesis by recruiting endothelial progenitor cells (EPCs) in breast cancer, thereby providing sufficient nutrients to fuel tumor growth and metastasis. Furthermore, after mice bearing breast cancer were treated with antibodies targeting CXCL12, reduced tumor volume and cell number were observed (Orimo et al., 2005). It was reported that CAF-derived CXCL12 activated TGF- $\beta$-regulated C-X-C chemokine receptor type 4 (CXCR4) expression in human prostatic epithelial BPH-1 cells to induce tumorigenesis. The CAF-conditioned medium was sufficient to induce CXCR4-AKT activation in BPH-1 cells in vitro. In vivo tumor grafting experiments also supported this claim. CXCR4-deficient prostate tumors were significantly smaller and less invasive as compared to control tumors, confirming the role of the CXCL12-CXCR4 axis in initiating tumor formation (Ao et al., 2007). The EMT process represents a pivotal mechanism used by cancer cells for migration and invasion. It was shown in vitro that CAF-derived CXCL12 functions as an important EMT inducer in breast cancer cells by regulating the Wnt/ $\beta$-catenin signaling pathway (Shan et al., 2015). TGF- $\beta$ is another multifunctional cytokine that is well-known for its role in inducing the EMT process. CAF-derived TGF- $\beta 1$ promoted the aggressive phenotypes of breast cancer cells by inducing EMT through the activation of TGF- $\beta /$ SMAD signaling. The EMT phenotype was reversed in the cells after the addition of TGF- $\beta 1$ neutralizing antibody (Yu et al., 2014).

\section{THERAPEUTIC PERSPECTIVES: TARGETING THE ECM MICROENVIRONMENT}

Despite the growing enthusiasm for the development of CAF-targeting therapies, targeting CAFs has been challenging and lacks real and meaningful progress. One interesting example is FAP. Murine anti-FAP antibody F19 showed a significant tumor-inhibitory effect in xenograft models of lung, pancreas, and head and neck cancers with no obvious signs of toxicity (Ostermann et al., 2008). Because of promising pre-clinical data, a humanized version of murine anti-FAP antibody, sibrotuzumab, has been designed and tested in a phase I clinical trial and was determined to be safe and tolerable (Scott et al., 2003). However, in the phase II study in metastatic colorectal cancer, sibrotuzumab showed no therapeutic benefits (Hofheinz et al., 2003). Therefore, instead of targeting a specific subset of CAFs or CAFs in general, identifying the exact mechanisms that CAFs use to support cancer cells may help to develop better therapeutic strategies, e.g., based on CAF autophagy (Zhang et al., 2018), or based on the specific ECM proteins that are produced by CAFs.

\section{TARGETING ECM PROTEINS}

Humanized anti-collagen antibodies and ECM inhibitors have emerged as promising agents for cancer therapy (de Jonge et al., 2006; Koon et al., 2011). Halofuginone is an inhibitor of collagen I and was shown having anti-tumor activities in mouse models of prostate cancer (Gavish et al., 2002), pancreatic cancer (Spector et al., 2010) and lung cancer (Taras et al., 
2006). D93/TRC093 is a humanized monoclonal antibody that specifically binds the HU177 cryptic collagen epitope within the tumor ECM with potential antiangiogenic and antitumor activities (Cretu et al., 2007; Caron et al., 2016). In the study conducted by Caron et al. (2016) D93/TRC093 was found to restrict the accumulation of $\alpha$-SMA + fibroblasts, which could be explained by the inhibition of integrin $\alpha_{10} \beta_{1}$-mediated fibroblast adhesion and migration on denatured collagen. In a phase I clinical study, TRC093 was shown to be well-tolerated and had tumor-inhibitory effects as monotherapy and in combination with bevacizumab in 19 patients carrying different types of solid tumors (Robert et al., 2010).

Conjugating a monoclonal antibody with a cell-killing agent is a new approach to develop novel targeted anti-cancer agents. In the past two decades, FN1-targeting antibodies have been designed and tested in different models. L19 is a monoclonal antibody known to target the ED-B domain of FN1. By attaching anti-angiogenesis drugs to L19, the fusion protein was demonstrated to exhibit strong anti-tumor effects in animal models carrying different tumors, including teratocarcinoma, colon adenocarcinoma and sarcoma (Birchler et al., 1999). Interleukin-2 (IL-2) is a cytokine factor and an important player in anticancer immunity. However, the cardiovascular toxicity of IL-2 remains a major clinical issue. To overcome this problem, a new strategy was designed by fusing IL-2 with L19 so that IL-2 can be precisely targeted to the tumor site, resulting in reduced side effects. This drug conjugate exerted strong immune-stimulatory effects and inhibited tumor growth in stage III melanoma patients (Danielli et al., 2015). Currently, L19-IL-2 in combination with L19-TNF is in a phase III clinical trial to evaluate its efficacy against advanced melanoma (ClinicalTrials.gov Identifier: NCT03567889). Similarly, TNC-targeting antibodies have also been conjugated with IL-2, and have shown some preliminary signs of anti-tumor activity in advanced solid tumors and metastatic breast cancer (Catania et al., 2015). Navitoclax (ABT-263) is a small molecule that was shown to have the ability to induce apoptosis in myofibroblasts (Lagares et al., 2017). Consequently, Navitoclax could be used to target CAFs in solid tumor. Navitoclax-loaded nanoliposome was modified with peptide FH (FH-SSL-Nav), which specifically binds to TNC, to precisely eradicate CAFs at the tumor site. Using a xenograft mouse model of hepatocellular cancer, FH-SSL-Nav was shown to have the ability to deplete CAFs and inhibit tumor growth (Chen et al., 2016). In January 2017, the National Cancer Institute (NCI) approved a phase Ib/II trial study to evaluate the side effects and best dose of the combination of MEK inhibitor Trametinib and Navitoclax in treating patients with advanced or metastatic solid tumors (ClinicalTrials.gov Identifier: NCT02079740).

\section{TARGETING ECM REMODELING ENZYMES}

Extracellular matrix remodeling plays an essential role in CAF-mediated desmoplastic reactions, which cannot be achieved without LOX-induced ECM crosslinking. LOX inhibitors have emerged as potential alternatives to target the desmoplastic
TME and improve drug delivery efficacy. In an in vitro $3 \mathrm{D}$ spheroid model using four different mouse tumor cell lines, including Lewis lung carcinoma cell line (LLC), a fibrosarcoma cell line (MT6) and two breast carcinoma cell lines (4T1, EMT6), LOX inhibition significantly improved the diffusion of doxorubicin (Schutze et al., 2015). Blocking LOX family oxidases in vitro or in vivo has shown potent anti-tumor activities in breast and pancreatic cancer (Park et al., 2016; Chang et al., 2017). Nevertheless, caution should still be taken when considering using LOX inhibitors. In a rat model of prostate cancer, LOX inhibition seems to have contextdependent effects during different stages of tumor progression. Before tumor formation, LOX inhibitors showed strong tumorinhibiting capacity. To the contrary, after prostate tumors were established, LOX inhibition did not affect or decrease tumor growth (Nilsson et al., 2016). In recent clinical trials, simtuzumab, a monoclonal antibody against LOXL2, failed to produce improved anti-tumor benefits when given in combination with other anti-cancer drugs, including 5-fluorouracil, leucovorin, irinotecan (FOLFIRI) and gemcitabine (Benson et al., 2017; Hecht et al., 2017).

Many MMPs have been known to be notorious for their roles in promoting cancer progression. As a result, more than $50 \mathrm{MMP}$ inhibitors were investigated in clinical trials. In a pre-clinical study, an anti-MMP9 monoclonal antibody GS-5745 successfully inhibited tumor growth and reduced tumor metastasis in mice bearing colorectal tumors (Marshall et al., 2015). Nevertheless, despite exciting preclinical data, none of these MMP inhibitors displayed anti-tumor effects in clinical trials. Although there are many explanations for these failures, such as bad clinical trial design, poor oral bioavailability, and inadequate cancer stages (Vandenbroucke and Libert, 2014), one potential reason responsible for the failures of these MMP inhibitors might be the obscurity of the roles and functions of MMPs in the ECM microenvironment. In addition, the use of broadspectrum MMP inhibitors also suppresses potential tumorinhibiting MMPs. Therefore, although MMPs are attractive therapeutic targets, more research is needed to unravel the roles of different MMPs in different cancer types and/or during various cancer stages. Furthermore, more efforts are required to develop more specific and selective MMP inhibitors to avoid potential side effects.

\section{TARGETING CAF-DERIVED MOLECULAR SIGNALS}

Cancer-associated fibroblast-mediated paracrine signaling has also been envisioned as a potential target in cancer treatment. In a recent phase I-II study on myeloid leukemia, plerixafor, a CXCR4 inhibitor, resulted in improved recovery rate when given in combination with a FLAG-Ida regime (fludarabine, idarubicin, cytarabine, and G-CSF) (Martinez-Cuadron et al., 2018). To block TGF- $\beta$ activity, TGF- $\beta$ inhibitors and monoclonal antibodies have been designed and tested in clinical trials. Galunisertib, a TGF- $\beta$ receptor kinase inhibitor, however, showed highly context-dependent tumor-inhibitory effects. While it 
showed promising clinical responses in neuroblastoma patients (Tran et al., 2017), galunisertib had no significant therapeutic effect in a phase II clinical study in recurrent glioblastoma patients (Brandes et al., 2016). The monoclonal antibody fresolimumab (GC1008), which is capable of neutralizing all human isoforms of TGF- $\beta$, has also been investigated in advanced malignant melanoma and renal cell carcinoma and showed early stage anti-tumor effects with no dose-limiting toxicity in a phase I clinical study (Morris et al., 2014). In 2017, several clinical trials investigating an anti-HGF antibody, rilotumumab, were published. In one clinical trial, improved antitumor activities of rilotumumab in combination with cisplatin and capecitabine were shown in patients with MET-positive advanced gastric or gastroesophageal junction cancer (Doi et al., 2017). The combined use of rilotumumab with erlotinib (an EGFR receptor inhibitor) also showed successes in treating advanced NSCLC (Tarhini et al., 2017). However, in another clinical trial on small-cell lung cancer patients, no significant clinical benefit of rilotumumab in combination with platinum-based chemotherapy was observed (Glisson et al., 2017). Similarly, in a phase III clinical study, the treatment utilizing rilotumumab plus epirubicin, cisplatin, and capecitabine as a first-line therapy on gastric or gastro-oesophageal junction cancer patients was unsuccessful (Catenacci et al., 2017). Taken together, targeting CAF-induced paracrine signaling appears to be spatial-temporal and case-dependent.

\section{REFERENCES}

Ao, M., Franco, O. E., Park, D., Raman, D., Williams, K., and Hayward, S. W. (2007). Cross-talk between paracrine-acting cytokine and chemokine pathways promotes malignancy in benign human prostatic epithelium. Cancer Res. 67, 4244-4253. doi: 10.1158/0008-5472.CAN-06-3946

Ashley, S. L., Wilke, C. A., Kim, K. K., and Moore, B. B. (2017). Periostin regulates fibrocyte function to promote myofibroblast differentiation and lung fibrosis. Mucosal Immunol. 10, 341-351. doi: 10.1038/mi.2016.61

Attieh, Y., Clark, A. G., Grass, C., Richon, S., Pocard, M., Mariani, P., et al. (2017). Cancer-associated fibroblasts lead tumor invasion through integrinbeta3-dependent fibronectin assembly. J. Cell Biol. 216, 3509-3520. doi: 10. 1083/jcb.201702033

Barczyk, M., Carracedo, S., and Gullberg, D. (2010). Integrins. Cell Tissue Res. 339, 269-280. doi: 10.1007/s00441-009-0834-6

Barry-Hamilton, V., Spangler, R., Marshall, D., McCauley, S., Rodriguez, H. M., Oyasu, M., et al. (2010). Allosteric inhibition of lysyl oxidase-like-2 impedes the development of a pathologic microenvironment. Nat. Med. 16, 1009-1017. doi: $10.1038 / \mathrm{nm} .2208$

Bates, A. L., Pickup, M. W., Hallett, M. A., Dozier, E. A., Thomas, S., and Fingleton, B. (2015). Stromal matrix metalloproteinase 2 regulates collagen expression and promotes the outgrowth of experimental metastases. J. Pathol. 235, 773-783. doi: 10.1002/path.4493

Bauer, M., Su, G., Casper, C., He, R., Rehrauer, W., and Friedl, A. (2010). Heterogeneity of gene expression in stromal fibroblasts of human breast carcinomas and normal breast. Oncogene 29, 1732-1740. doi: 10.1038/onc. 2009.463

Baum, J., and Duffy, H. S. (2011). Fibroblasts and myofibroblasts: what are we talking about? J. Cardiovasc. Pharmacol. 57, 376-379. doi: 10.1097/FJC. 0b013e3182116e39

Belkin, A. M., and Stepp, M. A. (2000). Integrins as receptors for laminins. Microsc. Res. Tech. 51, 280-301.

Bellomo, C., Caja, L., and Moustakas, A. (2016). Transforming growth factor beta as regulator of cancer stemness and metastasis. Br. J. Cancer 115, 761-769. doi: $10.1038 /$ bjc. 2016.255

\section{CONCLUSION}

It is an astonishing feat of the tumor cells to abandon the basic rules of tissue homeostasis and to grow uncontrollably. Unfortunately, as we have learned from many modern targeted therapies, a simple approach to eliminate tumor "seed" is generally condemned to failure. It is becoming clear that the TME is actively involved in tumor initiation, progression, metastasis and the development of drug resistance. However, only after gaining enhanced knowledge about the TME, including the heterogeneous nature and complexity of CAF populations, a multiplex approach targeting CAFs and the ECM will naturally come by and provide desired clinical benefits.

\section{AUTHOR CONTRIBUTIONS}

All authors listed have made a substantial, direct and intellectual contribution to the work, and approved it for publication.

\section{FUNDING}

This work was supported by CCTST Pilot Translational Research \& Innovative Core Grant (YZ) and NIH R15CA228014 (YZ).

Benito-Jardon, M., Klapproth, S., Gimeno, L. I., Petzold, T., Bharadwaj, M., Muller, D. J., et al. (2017). The fibronectin synergy site re-enforces cell adhesion and mediates a crosstalk between integrin classes. eLife 6:e22264. doi: 10.7554/eLife. 22264

Benson, A. B. III, Wainberg, Z. A., Hecht, J. R., Vyushkov, D., Dong, H., Bendell, J., et al. (2017). A phase II randomized, double-blind, placebo-controlled study of simtuzumab or placebo in combination with gemcitabine for the first-line treatment of pancreatic adenocarcinoma. Oncologist 22, 241-e15. doi: 10.1634/ theoncologist.2017-0024

Biffi, G., Oni, T. E., Spielman, B., Hao, Y., Elyada, E., Park, Y., et al. (2019). IL1-induced JAK/STAT signaling is antagonized by TGFbeta to shape CAF heterogeneity in pancreatic ductal adenocarcinoma. Cancer Discov. 9, 282-301. doi: 10.1158/2159-8290.CD-18-0710

Birchler, M., Viti, F., Zardi, L., Spiess, B., and Neri, D. (1999). Selective targeting and photocoagulation of ocular angiogenesis mediated by a phagederived human antibody fragment. Nat. Biotechnol. 17, 984-988. doi: 10.1038/ 13679

Botti, G., Cerrone, M., Scognamiglio, G., Anniciello, A., Ascierto, P. A., and Cantile, M. (2013). Microenvironment and tumor progression of melanoma: new therapeutic prospectives. J. Immunotoxicol. 10, 235-252. doi: 10.3109/ 1547691X.2012.723767

Brandes, A. A., Carpentier, A. F., Kesari, S., Sepulveda-Sanchez, J. M., Wheeler, H. R., Chinot, O., et al. (2016). A phase II randomized study of galunisertib monotherapy or galunisertib plus lomustine compared with lomustine monotherapy in patients with recurrent glioblastoma. Neuro Oncol. 18, 1146-1156. doi: 10.1093/neuonc/now009

Brellier, F., Hostettler, K., Hotz, H. R., Ozcakir, C., Cologlu, S. A., Togbe, D., et al. (2011). Tenascin-C triggers fibrin accumulation by downregulation of tissue plasminogen activator. FEBS Lett. 585, 913-920. doi: 10.1016/j.febslet.2011.02.023

Cai, J., Du, S., Wang, H., Xin, B., Wang, J., Shen, W., et al. (2017). Tenascin$\mathrm{C}$ induces migration and invasion through JNK/c-Jun signalling in pancreatic cancer. Oncotarget 8, 74406-74422. doi: 10.18632/oncotarget.20160

Calvo, F., Ege, N., Grande-Garcia, A., Hooper, S., Jenkins, R. P., Chaudhry, S. I., et al. (2013). Mechanotransduction and YAP-dependent matrix 
remodelling is required for the generation and maintenance of cancerassociated fibroblasts. Nat. Cell Biol. 15, 637-646. doi: 10.1038/ncb 2756

Caron, J. M., Ames, J. J., Contois, L., Liebes, L., Friesel, R., Muggia, F., et al. (2016). Inhibition of ovarian tumor growth by targeting the HU177 cryptic collagen epitope. Am. J. Pathol. 186, 1649-1661. doi: 10.1016/j.ajpath.2016.01.015

Carracedo, S., Lu, N., Popova, S. N., Jonsson, R., Eckes, B., and Gullberg, D. (2010). The fibroblast integrin alphallbetal is induced in a mechanosensitive manner involving activin A and regulates myofibroblast differentiation. J. Biol. Chem. 285, 10434-10445. doi: 10.1074/jbc.M109.078766

Catania, C., Maur, M., Berardi, R., Rocca, A., Giacomo, A. M., Spitaleri, G., et al. (2015). The tumor-targeting immunocytokine F16-IL2 in combination with doxorubicin: dose escalation in patients with advanced solid tumors and expansion into patients with metastatic breast cancer. Cell Adh. Migr. 9, 14-21. doi: $10.4161 / 19336918.2014 .983785$

Catenacci, D. V. T., Tebbutt, N. C., Davidenko, I., Murad, A. M., Al-Batran, S. E., Ilson, D. H., et al. (2017). Rilotumumab plus epirubicin, cisplatin, and capecitabine as first-line therapy in advanced MET-positive gastric or gastrooesophageal junction cancer (RILOMET-1): a randomised, double-blind, placebo-controlled, phase 3 trial. Lancet Oncol. 18, 1467-1482. doi: 10.1016/ S1470-2045(17)30566-1

Chang, J., Lucas, M. C., Leonte, L. E., Garcia-Montolio, M., Singh, L. B., Findlay, A. D., et al. (2017). Pre-clinical evaluation of small molecule LOXL2 inhibitors in breast cancer. Oncotarget 8, 26066-26078. doi: 10.18632/oncotarget.15257

Chen, B., Wang, Z., Sun, J., Song, Q., He, B., Zhang, H., et al. (2016). A tenascin $\mathrm{C}$ targeted nanoliposome with navitoclax for specifically eradicating of cancer-associated fibroblasts. Nanomedicine 12, 131-141. doi: 10.1016/j.nano.2015.10.001

Chen, S. Z., Yao, H. Q., Zhu, S. Z., Li, Q. Y., Guo, G. H., and Yu, J. (2015). Expression levels of matrix metalloproteinase-9 in human gastric carcinoma. Oncol. Lett. 9, 915-919. doi: 10.3892/ol.2014.2768

Chen, Y., Wang, X., Chen, G., Dong, C., and Zhang, D. (2015). The impact of matrix metalloproteinase 2 on prognosis and clinicopathology of breast cancer patients: a systematic meta-analysis. PLoS One 10:e0121404. doi: 10 . 1371/journal.pone.0121404

Choe, C., Shin, Y. S., Kim, S. H., Jeon, M. J., Choi, S. J., Lee, J., et al. (2013). Tumorstromal interactions with direct cell contacts enhance motility of non-small cell lung cancer cells through the hedgehog signaling pathway. Anticancer Res. 33, 3715-3723.

Costa, A., Kieffer, Y., Scholer-Dahirel, A., Pelon, F., Bourachot, B., Cardon, M., et al. (2018). Fibroblast heterogeneity and immunosuppressive environment in human breast cancer. Cancer Cell 33, 463-479.e10. doi: 10.1016/j.ccell.2018.01.011

Cretu, A., Roth, J. M., Caunt, M., Akalu, A., Policarpio, D., Formenti, S., et al. (2007). Disruption of endothelial cell interactions with the novel HU177 cryptic collagen epitope inhibits angiogenesis. Clin. Cancer Res. 13, 3068-3078. doi: 10.1158/1078-0432.CCR-06-2342

Danen, E. H., van Rheenen, J., Franken, W., Huveneers, S., Sonneveld, P., Jalink, K., et al. (2005). Integrins control motile strategy through a Rho-cofilin pathway. J. Cell Biol. 169, 515-526. doi: 10.1083/jcb.200412081

Danielli, R., Patuzzo, R., Di Giacomo, A. M., Gallino, G., Maurichi, A., Di Florio, A., et al. (2015). Intralesional administration of L19-IL2/L19-TNF in stage III or stage IVM1 a melanoma patients: results of a phase II study. Cancer Immunol. Immunother. 64, 999-1009. doi: 10.1007/s00262-015-1704-6

Darby, I. A., Laverdet, B., Bonte, F., and Desmouliere, A. (2014). Fibroblasts and myofibroblasts in wound healing. Clin. Cosmet. Investig. Dermatol. 7, 301-311. doi: 10.2147/CCID.S50046

de Groot, A. E., Roy, S., Brown, J. S., Pienta, K. J., and Amend, S. R. (2017). Revisiting seed and soil: examining the primary tumor and cancer cell foraging in metastasis. Mol. Cancer Res. 15, 361-370. doi: 10.1158/1541-7786.MCR-160436

de Jonge, M. J., Dumez, H., Verweij, J., Yarkoni, S., Snyder, D., Lacombe, D., et al. (2006). Phase I and pharmacokinetic study of halofuginone, an oral quinazolinone derivative in patients with advanced solid tumours. Eur. J. Cancer 42, 1768-1774. doi: 10.1016/j.ejca.2005.12.027

De Palma, M., Biziato, D., and Petrova, T. V. (2017). Microenvironmental regulation of tumour angiogenesis. Nat. Rev. Cancer 17, 457-474. doi: 10.1038/ nrc.2017.51
Desmouliere, A., Redard, M., Darby, I., and Gabbiani, G. (1995). Apoptosis mediates the decrease in cellularity during the transition between granulation tissue and scar. Am. J. Pathol. 146, 56-66.

Doi, T., Yamaguchi, K., Komatsu, Y., Muro, K., Nishina, T., Nakajima, T. E., et al. (2017). A Phase $1 / 1 b$ tolerability study of rilotumumab alone or in combination with cisplatin and capecitabine in Japanese patients with gastric cancer. Jpn. J. Clin. Oncol. 47, 1002-1009. doi: 10.1093/jjco/hyx114

Dvorak, H. F. (1986). Tumors: wounds that do not heal. Similarities between tumor stroma generation and wound healing. N. Engl. J. Med. 315, 1650-1659. doi: 10.1056/NEJM198612253152606

Erdogan, B., Ao, M., White, L. M., Means, A. L., Brewer, B. M., Yang, L., et al. (2017). Cancer-associated fibroblasts promote directional cancer cell migration by aligning fibronectin. J. Cell Biol. 216, 3799-3816. doi: 10.1083/jcb.201704053

Faouzi, S., Le Bail, B., Neaud, V., Boussarie, L., Saric, J., Bioulac-Sage, P., et al. (1999). Myofibroblasts are responsible for collagen synthesis in the stroma of human hepatocellular carcinoma: an in vivo and in vitro study. J. Hepatol. 30, 275-284.

Flavell, R. A., Sanjabi, S., Wrzesinski, S. H., and Licona-Limon, P. (2010). The polarization of immune cells in the tumour environment by TGFbeta. Nat. Rev. Immunol. 10, 554-567. doi: 10.1038/nri2808

Foster, D. S., Jones, R. E., Ransom, R. C., Longaker, M. T., and Norton, J. A. (2018). The evolving relationship of wound healing and tumor stroma. JCI Insight 3:99911. doi: 10.1172/jci.insight.99911

Fu, Z., Xu, S., Xu, Y., Ma, J., Li, J., and Xu, P. (2015). The expression of tumorderived and stromal-derived matrix metalloproteinase 2 predicted prognosis of ovarian cancer. Int. J. Gynecol. Cancer 25, 356-362. doi: 10.1097/IGC. 0000000000000386

Fukino, K., Shen, L., Matsumoto, S., Morrison, C. D., Mutter, G. L., and Eng, C. (2004). Combined total genome loss of heterozygosity scan of breast cancer stroma and epithelium reveals multiplicity of stromal targets. Cancer Res. 64, 7231-7236. doi: 10.1158/0008-5472.CAN-04-2866

Fullar, A., Dudas, J., Olah, L., Hollosi, P., Papp, Z., Sobel, G., et al. (2015). Remodeling of extracellular matrix by normal and tumor-associated fibroblasts promotes cervical cancer progression. BMC Cancer 15:256. doi: 10.1186/ s12885-015-1272-3

Gao, A. E., Sullivan, K. E., and Black, L. D. III (2016). Lysyl oxidase expression in cardiac fibroblasts is regulated by alpha2betal integrin interactions with the cellular microenvironment. Biochem. Biophys. Res. Commun. 475, 70-75. doi: 10.1016/j.bbrc.2016.05.037

Gavish, Z., Pinthus, J. H., Barak, V., Ramon, J., Nagler, A., Eshhar, Z., et al. (2002). Growth inhibition of prostate cancer xenografts by halofuginone. Prostate 51, 73-83. doi: 10.1002/pros.10059

Glisson, B., Besse, B., Dols, M. C., Dubey, S., Schupp, M., Jain, R., et al. (2017). A randomized, placebo-controlled, phase $1 \mathrm{~b} / 2$ study of rilotumumab or ganitumab in combination with platinum-based chemotherapy as first-line treatment for extensive-stage small-cell lung cancer. Clin. Lung Cancer 18, 615-625.e8. doi: 10.1016/j.cllc.2017.05.007

Gong, L., Wu, D., Zou, J., Chen, J., Chen, L., Chen, Y., et al. (2016). Prognostic impact of serum and tissue MMP-9 in non-small cell lung cancer: a systematic review and meta-analysis. Oncotarget 7, 18458-18468. doi: 10.18632/ oncotarget.7607

Gozdzialska, A., Wojas-Pelc, A., Drag, J., Brzewski, P., Jaskiewicz, J., and Pastuszczak, M. (2016). Expression of metalloproteinases (MMP-2 and MMP-9) in basal-cell carcinoma. Mol. Biol. Rep. 43, 1027-1033. doi: 10.1007/s11033-016-4040-9

Groblewska, M., Mroczko, B., Gryko, M., Pryczynicz, A., GuzinskaUstymowicz, K., Kedra, B., et al. (2014). Serum levels and tissue expression of matrix metalloproteinase 2 (MMP-2) and tissue inhibitor of metalloproteinases 2 (TIMP-2) in colorectal cancer patients. Tumour Biol. 35, 3793-3802. doi: 10.1007/s13277-013-1502-8

Harper, R. A., and Grove, G. (1979). Human skin fibroblasts derived from papillary and reticular dermis: differences in growth potential in vitro. Science 204, 526-527. doi: 10.1126/science.432659

Hecht, J. R., Benson, A. B. III, Vyushkov, D., Yang, Y., Bendell, J., and Verma, U. (2017). A phase II, randomized, double-blind, placebo-controlled study of simtuzumab in combination with FOLFIRI for the second-line treatment of metastatic KRAS mutant colorectal adenocarcinoma. Oncologist 22, 243-e23. doi: 10.1634/theoncologist.2016-0479 
Hikage, F., Atkins, S., Kahana, A., Smith, T. J., and Chun, T. H. (2019). HIF2A-LOX pathway promotes fibrotic tissue remodeling in thyroid-associated orbitopathy. Endocrinology 160, 20-35. doi: 10.1210/en.2018-00272

Hinz, B., Phan, S. H., Thannickal, V. J., Galli, A., Bochaton-Piallat, M. L., and Gabbiani, G. (2007). The myofibroblast: one function, multiple origins. Am. J. Pathol. 170, 1807-1816. doi: 10.2353/ajpath.2007.070112

Hofheinz, R. D., al-Batran, S. E., Hartmann, F., Hartung, G., Jager, D., Renner, C., et al. (2003). Stromal antigen targeting by a humanised monoclonal antibody: an early phase II trial of sibrotuzumab in patients with metastatic colorectal cancer. Onkologie 26, 44-48. doi: 10.1159/000069863

Hsia, L. T., Ashley, N., Ouaret, D., Wang, L. M., Wilding, J., and Bodmer, W. F. (2016). Myofibroblasts are distinguished from activated skin fibroblasts by the expression of AOC3 and other associated markers. Proc. Natl. Acad. Sci. U.S.A. 113, E2162-E2171. doi: 10.1073/pnas.1603534113

Ito, M., Ishii, G., Nagai, K., Maeda, R., Nakano, Y., and Ochiai, A. (2012). Prognostic impact of cancer-associated stromal cells in patients with stage I lung adenocarcinoma. Chest 142, 151-158. doi: 10.1378/chest.11-2458

Iwaisako, K., Brenner, D. A., and Kisseleva, T. (2012). What's new in liver fibrosis? The origin of myofibroblasts in liver fibrosis. J. Gastroenterol. Hepatol. 27(Suppl. 2), 65-68. doi: 10.1111/j.1440-1746.2011.07002.x

Iyer, R. P., Patterson, N. L., Fields, G. B., and Lindsey, M. L. (2012). The history of matrix metalloproteinases: milestones, myths, and misperceptions. Am. J. Physiol. Heart Circ. Physiol. 303, H919-H930. doi: 10.1152/ajpheart.00577.2012

Jakubowska, K., Pryczynicz, A., Januszewska, J., Sidorkiewicz, I., Kemona, A., Niewinski, A., et al. (2016). Expressions of matrix metalloproteinases 2, 7 , and 9 in carcinogenesis of pancreatic ductal adenocarcinoma. Dis. Markers 2016:9895721. doi: 10.1155/2016/9895721

Janson, D. G., Saintigny, G., van Adrichem, A., Mahe, C., and El Ghalbzouri, A. (2012). Different gene expression patterns in human papillary and reticular fibroblasts. J. Invest. Dermatol. 132, 2565-2572. doi: 10.1038/jid.2012.192

Kamyab-Hesari, K., Mohtasham, N., Aghazadeh, N., Biglarian, M., Memar, B., and Kadeh, H. (2014). The expression of MMP-2 and Ki-67 in head and neck melanoma, and their correlation with clinic-pathologic indices. J. Cancer Res. Ther. 10, 696-700. doi: 10.4103/0973-1482.138122

Kanisicak, O., Khalil, H., Ivey, M. J., Karch, J., Maliken, B. D., Correll, R. N., et al. (2016). Genetic lineage tracing defines myofibroblast origin and function in the injured heart. Nat. Commun. 7:12260. doi: 10.1038/ncomms12260

Kasashima, H., Yashiro, M., Kinoshita, H., Fukuoka, T., Morisaki, T., Masuda, G., et al. (2014). Lysyl oxidase-like 2 (LOXL2) from stromal fibroblasts stimulates the progression of gastric cancer. Cancer Lett. 354, 438-446. doi: 10.1016/j. canlet.2014.08.014

Koon, H. B., Fingleton, B., Lee, J. Y., Geyer, J. T., Cesarman, E., Parise, R. A., et al. (2011). Phase II AIDS Malignancy Consortium trial of topical halofuginone in AIDS-related Kaposi sarcoma. J. Acquir. Immune Defic. Syndr. 56, 64-68. doi: 10.1097/QAI.0b013e3181fc0141

Korosec, A., Frech, S., Gesslbauer, B., Vierhapper, M., Radtke, C., Petzelbauer, P., et al. (2019). Lineage identity and location within the dermis determine the function of papillary and reticular fibroblasts in human skin. J. Invest. Dermatol. 139, 342-351. doi: 10.1016/j.jid.2018.07.033

Kumar, P., Smith, T., Raeman, R., Chopyk, D. M., Brink, H., Liu, Y., et al. (2018). Periostin promotes liver fibrogenesis by activating lysyl oxidase in hepatic stellate cells. J. Biol. Chem. 293, 12781-12792. doi: 10.1074/jbc.RA117.001601

Labernadie, A., Kato, T., Brugues, A., Serra-Picamal, X., Derzsi, S., Arwert, E., et al. (2017). A mechanically active heterotypic E-cadherin/N-cadherin adhesion enables fibroblasts to drive cancer cell invasion. Nat. Cell Biol. 19, 224-237. doi: $10.1038 /$ ncb3478

Lagares, D., Santos, A., Grasberger, P. E., Liu, F., Probst, C. K., Rahimi, R. A., et al. (2017). Targeted apoptosis of myofibroblasts with the BH3 mimetic ABT263 reverses established fibrosis. Sci. Transl. Med. 9:eaal3765. doi: 10.1126/ scitranslmed.aal3765

Lambrechts, D., Wauters, E., Boeckx, B., Aibar, S., Nittner, D., Burton, O., et al. (2018). Phenotype molding of stromal cells in the lung tumor microenvironment. Nat. Med. 24, 1277-1289. doi: 10.1038/s41591-018-0096-5

LeBleu, V. S., and Kalluri, R. (2018). A peek into cancer-associated fibroblasts: origins, functions and translational impact. Dis. Model. Mech. 11:dmm029447. doi: $10.1242 / \mathrm{dmm} .029447$

Lee, C. Y., Shim, H. S., Lee, S., Lee, J. G., Kim, D. J., and Chung, K. Y. (2015). Prognostic effect of matrix metalloproteinase-9 in patients with resected Non small cell lung cancer. J. Cardiothorac. Surg. 10:44. doi: 10.1186/s13019-0150248-3

Leitinger, B. (2011). Transmembrane collagen receptors. Annu. Rev. Cell Dev. Biol. 27, 265-290. doi: 10.1146/annurev-cellbio-092910-154013

Li, H., Courtois, E. T., Sengupta, D., Tan, Y., Chen, K. H., Goh, J. J. L., et al. (2017). Reference component analysis of single-cell transcriptomes elucidates cellular heterogeneity in human colorectal tumors. Nat. Genet. 49, 708-718. doi: 10.1038/ng.3818

Li, Q., Chen, B., Cai, J., Sun, Y., Wang, G., Li, Y., et al. (2016). Comparative analysis of matrix metalloproteinase family members reveals that MMP9 predicts survival and response to temozolomide in patients with primary glioblastoma. PLoS One 11:e0151815. doi: 10.1371/journal.pone.0151815

Li, S., Shen, X., Yang, Z., Wu, A., Tang, Z., Li, M., et al. (2014). [Clinical significance of MMP2 overexpression in endometrial adenocarcinoma]. Nan Fang Yi Ke Da Хие Xие Bao 34, 423-425.

Liu, H. Y., Gu, W. J., Wang, C. Z., Ji, X. J., and Mu, Y. M. (2016). Matrix metalloproteinase- 9 and -2 and tissue inhibitor of matrix metalloproteinase2 in invasive pituitary adenomas: a systematic review and meta-analysis of case-control trials. Medicine 95:e3904. doi: 10.1097/MD.0000000000003904

Marshall, D. C., Lyman, S. K., McCauley, S., Kovalenko, M., Spangler, R., Liu, C., et al. (2015). Selective allosteric inhibition of MMP9 is efficacious in preclinical models of ulcerative colitis and colorectal cancer. PLoS One 10:e127063. doi: 10.1371/journal.pone. 0127063

Martinez-Cuadron, D., Boluda, B., Martinez, P., Bergua, J., Rodriguez-Veiga, R., Esteve, J., et al. (2018). A phase I-II study of plerixafor in combination with fludarabine, idarubicin, cytarabine, and G-CSF (PLERIFLAG regimen) for the treatment of patients with the first early-relapsed or refractory acute myeloid leukemia. Ann. Hematol. 97, 763-772. doi: 10.1007/s00277-018-3229-5

Matthijs Blankesteijn, W. (2015). Has the search for a marker of activated fibroblasts finally come to an end? J. Mol. Cell Cardiol. 88, 120-123. doi: 10. 1016/j.yjmcc.2015.10.005

McAnulty, R. J. (2007). Fibroblasts and myofibroblasts: their source, function and role in disease. Int. J. Biochem. Cell Biol. 39, 666-671. doi: 10.1016/j.biocel.2006. 11.005

McAnulty, R. J., Campa, J. S., Cambrey, A. D., and Laurent, G. J. (1991). The effect of transforming growth factor beta on rates of procollagen synthesis and degradation in vitro. Biochim. Biophys. Acta 1091, 231-235.

Menzin, A. W., Loret, de Mola, J. R., Bilker, W. B., Wheeler, J. E., Rubin, S. C., et al. (1998). Identification of oncofetal fibronectin in patients with advanced epithelial ovarian cancer: detection in ascitic fluid and localization to primary sites and metastatic implants. Cancer 82, 152-158.

Moore-Morris, T., Guimaraes-Camboa, N., Banerjee, I., Zambon, A. C., Kisseleva, T., Velayoudon, A., et al. (2014). Resident fibroblast lineages mediate pressure overload-induced cardiac fibrosis. J. Clin. Invest. 124, 2921-2934. doi: $10.1172 / J C I 74783$

Mori, L., Bellini, A., Stacey, M. A., Schmidt, M., and Mattoli, S. (2005). Fibrocytes contribute to the myofibroblast population in wounded skin and originate from the bone marrow. Exp. Cell Res. 304, 81-90. doi: 10.1016/j.yexcr.2004.11.011

Morris, J. C., Tan, A. R., Olencki, T. E., Shapiro, G. I., Dezube, B. J., Reiss, M., et al. (2014). Phase I study of GC1008 (fresolimumab): a human anti-transforming growth factor-beta (TGFbeta) monoclonal antibody in patients with advanced malignant melanoma or renal cell carcinoma. PLoS One 9:e90353. doi: 10.1371/ journal.pone. 0090353

Neri, S., Ishii, G., Hashimoto, H., Kuwata, T., Nagai, K., Date, H., et al. (2015). Podoplanin-expressing cancer-associated fibroblasts lead and enhance the local invasion of cancer cells in lung adenocarcinoma. Int. J. Cancer 137, 784-796. doi: 10.1002/ijc.29464

Ngo, M. A., Muller, A., Li, Y., Neumann, S., Tian, G., Dixon, I. M., et al. (2014). Human mesenchymal stem cells express a myofibroblastic phenotype in vitro: comparison to human cardiac myofibroblasts. Mol. Cell Biochem. 392, 187-204. doi: 10.1007/s11010-014-2030-6

Nguyen, X. X., Muhammad, L., Nietert, P. J., and Feghali-Bostwick, C. (2018). IGFBP-5 promotes fibrosis via increasing its own expression and that of other pro-fibrotic mediators. Front. Endocrinol. 9:601. doi: 10.3389/fendo.2018.00601

Ni, W. D., Yang, Z. T., Cui, C. A., Cui, Y., Fang, L. Y., and Xuan, Y. H. (2017). Tenascin-C is a potential cancer-associated fibroblasts marker and predicts poor prognosis in prostate cancer. Biochem. Biophys. Res. Commun. 486, 607-612. doi: 10.1016/j.bbrc.2017.03.021 
Nilsson, M., Adamo, H., Bergh, A., and Halin Bergstrom, S. (2016). Inhibition of lysyl oxidase and lysyl oxidase-like enzymes has tumour-promoting and tumour-suppressing roles in experimental prostate cancer. Sci. Rep. 6:19608. doi: $10.1038 /$ srep 19608

Nishio, K., Motozawa, K., Omagari, D., Gojoubori, T., Ikeda, T., Asano, M., et al. (2016). Comparison of MMP2 and MMP9 expression levels between primary and metastatic regions of oral squamous cell carcinoma. J. Oral Sci. 58, 59-65. doi: 10.2334/josnusd.58.59

Oguic, R., Mozetic, V., Cini Tesar, E., Fuckar Cupic, D., Mustac, E., and Dordevic, G. (2014). Matrix metalloproteinases 2 and 9 immunoexpression in prostate carcinoma at the positive margin of radical prostatectomy specimens. Patholog. Res. Int. 2014:262195. doi: 10.1155/2014/262195

Ohlund, D., Handly-Santana, A., Biffi, G., Elyada, E., Almeida, A. S., PonzSarvise, M., et al. (2017). Distinct populations of inflammatory fibroblasts and myofibroblasts in pancreatic cancer. J. Exp. Med. 214, 579-596. doi: 10.1084/ jem. 20162024

Organ, S. L., and Tsao, M. S. (2011). An overview of the c-MET signaling pathway. Ther. Adv. Med. Oncol. 3(Suppl. 1), S7-S19. doi: 10.1177/175883401142 2556

Orimo, A., Gupta, P. B., Sgroi, D. C., Arenzana-Seisdedos, F., Delaunay, T., Naeem, R., et al. (2005). Stromal fibroblasts present in invasive human breast carcinomas promote tumor growth and angiogenesis through elevated SDF1/CXCL12 secretion. Cell 121, 335-348. doi: 10.1016/j.cell.2005.02.034

Ostermann, E., Garin-Chesa, P., Heider, K. H., Kalat, M., Lamche, H., Puri, C., et al. (2008). Effective immunoconjugate therapy in cancer models targeting a serine protease of tumor fibroblasts. Clin. Cancer Res. 14, 4584-4592. doi: 10.1158/1078-0432.CCR-07-5211

Ozdemir, B. C., Pentcheva-Hoang, T., Carstens, J. L., Zheng, X., Wu, C. C., Simpson, T. R., et al. (2014). Depletion of carcinoma-associated fibroblasts and fibrosis induces immunosuppression and accelerates pancreas cancer with reduced survival. Cancer Cell 25, 719-734. doi: 10.1016/j.ccr.2014.04.005

Pankov, R., and Yamada, K. M. (2002). Fibronectin at a glance. J. Cell Sci. 115, 3861-3863. doi: 10.1242/jcs.00059

Park, J. S., Lee, J. H., Lee, Y. S., Kim, J. K., Dong, S. M., and Yoon, D. S. (2016). Emerging role of LOXL2 in the promotion of pancreas cancer metastasis. Oncotarget 7, 42539-42552. doi: 10.18632/oncotarget.9918

Paszek, M. J., Zahir, N., Johnson, K. R., Lakins, J. N., Rozenberg, G. I., Gefen, A., et al. (2005). Tensional homeostasis and the malignant phenotype. Cancer Cell 8, 241-254. doi: 10.1016/j.ccr.2005.08.010

Petersen, O. W., Nielsen, H. L., Gudjonsson, T., Villadsen, R., Ronnov-Jessen, L., and Bissell, M. J. (2001). The plasticity of human breast carcinoma cells is more than epithelial to mesenchymal conversion. Breast Cancer Res. 3, 213-217.

Philippeos, C., Telerman, S. B., Oules, B., Pisco, A. O., Shaw, T. J., Elgueta, R., et al. (2018). Spatial and single-cell transcriptional profiling identifies functionally distinct human dermal fibroblast subpopulations. J. Invest. Dermatol. 138, 811-825. doi: 10.1016/j.jid.2018.01.016

Pickup, M. W., Laklai, H., Acerbi, I., Owens, P., Gorska, A. E., Chytil, A., et al. (2013). Stromally derived lysyl oxidase promotes metastasis of transforming growth factor-beta-deficient mouse mammary carcinomas. Cancer Res. 73, 5336-5346. doi: 10.1158/0008-5472.CAN-13-0012

Pidsley, R., Lawrence, M. G., Zotenko, E., Niranjan, B., Statham, A., Song, J., et al. (2018). Enduring epigenetic landmarks define the cancer microenvironment. Genome Res. 28, 625-638. doi: 10.1101/gr.229070.117

Puram, S. V., Tirosh, I., Parikh, A. S., Patel, A. P., Yizhak, K., Gillespie, S., et al. (2017). Single-cell transcriptomic analysis of primary and metastatic tumor ecosystems in head and neck cancer. Cell 171, 1611-1624.e24. doi: 10.1016/j. cell.2017.10.044

Quante, M., Tu, S. P., Tomita, H., Gonda, T., Wang, S. S., Takashi, S., et al. (2011). Bone marrow-derived myofibroblasts contribute to the mesenchymal stem cell niche and promote tumor growth. Cancer Cell 19, 257-272. doi: 10.1016/j.ccr. 2011.01.020

Ramos, E. A., Silva, C. T., Manica, G. C., Pereira, I. T., Klassen, L. M., Ribeiro, E. M., et al. (2016). Worse prognosis in breast cancer patients can be predicted by immunohistochemical analysis of positive MMP-2 and negative estrogen and progesterone receptors. Rev. Assoc. Med. Bras. 62, 774-781. doi: 10.1590/18069282.62.08.774

Rao, S., Rao, J., Bm, J., and Vk, V. (2016). Mysterious myofibroblast: a cell with diverse origin and multiple functions. J. Interdiscip. Histopathol. 5, 12-17.
Robert, F., Gordon, M. S., Rosen, L. S., Mendelson, D. S., Mulay, M., Adams, B. J., et al. (2010). Final results from a phase I study of TRC093 (humanized anti-cleaved collagen antibody) in patients with solid cancer. J. Clin. Oncol. 28, 3038-3038. doi: 10.1200/jco.2010.28.15_suppl.3038

Ronnov-Jessen, L., and Petersen, O. W. (1993). Induction of alpha-smooth muscle actin by transforming growth factor-beta 1 in quiescent human breast gland fibroblasts. Implications for myofibroblast generation in breast neoplasia. $L a b$. Invest. 68, 696-707.

Salmenpera, P., Kankuri, E., Bizik, J., Siren, V., Virtanen, I., Takahashi, S., et al. (2008). Formation and activation of fibroblast spheroids depend on fibronectinintegrin interaction. Exp. Cell Res. 314, 3444-3452. doi: 10.1016/j.yexcr.2008. 09.004

Schafer, M., and Werner, S. (2008). Cancer as an overhealing wound: an old hypothesis revisited. Nat. Rev. Mol. Cell Biol. 9, 628-638. doi: 10.1038/nrm2455

Schutze, F., Rohrig, F., Vorlova, S., Gatzner, S., Kuhn, A., Ergun, S., et al. (2015). Inhibition of lysyl oxidases improves drug diffusion and increases efficacy of cytotoxic treatment in 3D tumor models. Sci. Rep. 5:17576. doi: 10.1038/ srep 17576

Scott, A. M., Wiseman, G., Welt, S., Adjei, A., Lee, F. T., Hopkins, W., et al. (2003). A Phase I dose-escalation study of sibrotuzumab in patients with advanced or metastatic fibroblast activation protein-positive cancer. Clin. Cancer Res. 9, 1639-1647.

Serres, E., Debarbieux, F., Stanchi, F., Maggiorella, L., Grall, D., Turchi, L., et al. (2014). Fibronectin expression in glioblastomas promotes cell cohesion, collective invasion of basement membrane in vitro and orthotopic tumor growth in mice. Oncogene 33, 3451-3462. doi: 10.1038/onc.2013.305

Shan, S., Lv, Q., Zhao, Y., Liu, C., Sun, Y., Xi, K., et al. (2015). Wnt/beta-catenin pathway is required for epithelial to mesenchymal transition in CXCL12 over expressed breast cancer cells. Int. J. Clin. Exp. Pathol. 8, 12357-12367.

Shattil, S. J., Kim, C., and Ginsberg, M. H. (2010). The final steps of integrin activation: the end game. Nat. Rev. Mol. Cell Biol. 11, 288-300. doi: 10.1038/ nrm 2871

Shiga, K., Hara, M., Nagasaki, T., Sato, T., Takahashi, H., and Takeyama, H. (2015). Cancer-associated fibroblasts: their characteristics and their roles in tumor growth. Cancers 7, 2443-2458. doi: 10.3390/cancers7040902

Spector, I., Honig, H., Kawada, N., Nagler, A., Genin, O., and Pines, M. (2010). Inhibition of pancreatic stellate cell activation by halofuginone prevents pancreatic xenograft tumor development. Pancreas 39, 1008-1015. doi: 10. 1097/MPA.0b013e3181da8aa3

Stanciu, A. E., Zamfir-Chiru-Anton, A., Stanciu, M. M., Popescu, C. R., and Gheorghe, D. C. (2016). Serum level of matrix metalloproteinase-9 in patients with head and neck squamous cell carcinoma. Clin. Lab. 62, 1569-1574. doi: 10.7754/Clin.Lab.2016.160139

Stenman, S., and Vaheri, A. (1981). Fibronectin in human solid tumors. Int. J. Cancer 27, 427-435.

Straussman, R., Morikawa, T., Shee, K., Barzily-Rokni, M., Qian, Z. R., Du, J., et al. (2012). Tumour micro-environment elicits innate resistance to RAF inhibitors through HGF secretion. Nature 487, 500-504. doi: 10.1038/nature11183

Sugihara, H., Ishimoto, T., Yasuda, T., Izumi, D., Eto, K., Sawayama, H., et al. (2015). Cancer-associated fibroblast-derived CXCL12 causes tumor progression in adenocarcinoma of the esophagogastric junction. Med. Oncol. 32:618. doi: 10.1007/s12032-015-0618-7

Sun, Q., Zhao, C., Xia, L., He, Z., Lu, Z., Liu, C., et al. (2014). High expression of matrix metalloproteinase-9 indicates poor prognosis in human hilar cholangiocarcinoma. Int. J. Clin. Exp. Pathol. 7, 6157-6164.

Tabib, T., Morse, C., Wang, T., Chen, W., and Lafyatis, R. (2018). SFRP2/DPP4 and FMO1/LSP1 define major fibroblast populations in human skin. J. Invest. Dermatol. 138, 802-810. doi: 10.1016/j.jid.2017.09.045

Tabouret, E., Bertucci, F., Pierga, J. Y., Petit, T., Levy, C., Ferrero, J. M., et al. (2016). MMP2 and MMP9 serum levels are associated with favorable outcome in patients with inflammatory breast cancer treated with bevacizumabbased neoadjuvant chemotherapy in the BEVERLY-2 study. Oncotarget 7, 18531-18540. doi: 10.18632/oncotarget.7612

Tabouret, E., Boudouresque, F., Barrie, M., Matta, M., Boucard, C., Loundou, A., et al. (2014). Association of matrix metalloproteinase 2 plasma level with response and survival in patients treated with bevacizumab for recurrent high-grade glioma. Neuro Oncol. 16, 392-399. doi: 10.1093/neuond not 226 
Taras, D., Blanc, J. F., Rullier, A., Dugot-Senant, N., Laurendeau, I., Bieche, I., et al. (2006). Halofuginone suppresses the lung metastasis of chemically induced hepatocellular carcinoma in rats through MMP inhibition. Neoplasia 8, 312-318. doi: 10.1593/neo.05796

Tarhini, A. A., Rafique, I., Floros, T., Tran, P., Gooding, W. E., Villaruz, L. C., et al. (2017). Phase $1 / 2$ study of rilotumumab (AMG 102), a hepatocyte growth factor inhibitor, and erlotinib in patients with advanced non-small cell lung cancer. Cancer 123, 2936-2944. doi: 10.1002/cncr.30717

Teng, F., Tian, W. Y., Wang, Y. M., Zhang, Y. F., Guo, F., Zhao, J., et al. (2016). Cancer-associated fibroblasts promote the progression of endometrial cancer via the SDF-1/CXCR4 axis. J. Hematol. Oncol. 9:8. doi: 10.1186/s13045-0150231-4

Torres, S., Garcia-Palmero, I., Herrera, M., Bartolome, R. A., Pena, C., FernandezAcenero, M. J., et al. (2015). LOXL2 is highly expressed in cancer-associated fibroblasts and associates to poor colon cancer survival. Clin. Cancer Res. 21, 4892-4902. doi: 10.1158/1078-0432.CCR-14-3096

Tran, H. C., Wan, Z., Sheard, M. A., Sun, J., Jackson, J. R., Malvar, J., et al. (2017). TGFbetaR1 blockade with galunisertib (LY2157299) enhances antineuroblastoma activity of the anti-GD2 antibody dinutuximab (ch14.18) with natural killer cells. Clin. Cancer Res. 23, 804-813. doi: 10.1158/1078-0432.CCR16- 1743

Tucker, R. P., and Chiquet-Ehrismann, R. (2015). Tenascin-C: its functions as an integrin ligand. Int. J. Biochem. Cell Biol. 65, 165-168. doi: 10.1016/j.biocel.2015. 06.003

Tyan, S. W., Kuo, W. H., Huang, C. K., Pan, C. C., Shew, J. Y., Chang, K. J., et al. (2011). Breast cancer cells induce cancer-associated fibroblasts to secrete hepatocyte growth factor to enhance breast tumorigenesis. PLoS One 6:e15313. doi: 10.1371/journal.pone.0015313

Valkenburg, K. C., de Groot, A. E., and Pienta, K. J. (2018). Targeting the tumour stroma to improve cancer therapy. Nat. Rev. Clin. Oncol. 15, 366-381. doi: 10.1038/s41571-018-0007-1

van Helvert, S., Storm, C., and Friedl, P. (2018). Mechanoreciprocity in cell migration. Nat. Cell Biol. 20, 8-20. doi: 10.1038/s41556-017-0012-0

Vandenbroucke, R. E., and Libert, C. (2014). Is there new hope for therapeutic matrix metalloproteinase inhibition? Nat. Rev. Drug Discov. 13, 904-927. doi: $10.1038 / \mathrm{nrd} 4390$

Wang, C., Ma, H. X., Jin, M. S., Zou, Y. B., Teng, Y. L., Tian, Z., et al. (2014). Association of matrix metalloproteinase (MMP)-2 and -9 expression with extra-gastrointestinal stromal tumor metastasis. Asian Pac. J. Cancer Prev. 15, 4187-4192.

Wang, J., Chen, H., Seth, A., and McCulloch, C. A. (2003). Mechanical force regulation of myofibroblast differentiation in cardiac fibroblasts. Am. J. Physiol. Heart Circ. Physiol. 285, H1871-H1881. doi: 10.1152/ajpheart.00387.2003

Wang, M., Wang, T., Liu, S., Yoshida, D., and Teramoto, A. (2003). The expression of matrix metalloproteinase- 2 and -9 in human gliomas of different pathological grades. Brain Tumor Pathol. 20, 65-72.

Wang, T. H., Hsia, S. M., and Shieh, T. M. (2016). Lysyl oxidase and the tumor microenvironment. Int J Mol Sci 18:62. doi: 10.3390/ijms18010062

Wells, R. G., and Schwabe, R. F. (2015). Origin and function of myofibroblasts in the liver. Semin. Liver Dis. 35, 97-106. doi: 10.1055/s-0035-1550061

Wen, X., Liu, Y., Bai, Y., Li, M., Fu, Q., and Zheng, Y. (2018). LOXL2, a copperdependent monoamine oxidase, activates lung fibroblasts through the TGFbeta/Smad pathway. Int. J. Mol. Med. 42, 3530-3541. doi: 10.3892/ijmm.2018. 3927

Wu, Q. W., Yang, Q. M., Huang, Y. F., She, H. Q., Liang, J., Yang, Q. L., et al. (2014). Expression and clinical significance of matrix metalloproteinase-9 in lymphatic invasiveness and metastasis of breast cancer. PLoS One 9:e97804. doi: 10.1371/journal.pone.0097804

Wu, X., Chen, X., Zhou, Q., Li, P., Yu, B., Li, J., et al. (2013). Hepatocyte growth factor activates tumor stromal fibroblasts to promote tumorigenesis in gastric cancer. Cancer Lett. 335, 128-135. doi: 10.1016/j.canlet.2013.02.002
Xing, F., Saidou, J., and Watabe, K. (2010). Cancer associated fibroblasts (CAFs) in tumor microenvironment. Front. Biosci. 15, 166-179.

Yamada, M., and Sekiguchi, K. (2015). "Chapter six - molecular basis of lamininintegrin interactions," in Current Topics in Membranes, ed. J. H. Miner (Cambridge, MA: Academic Press), 197-229.

Yang, X., Lin, Y., Shi, Y., Li, B., Liu, W., Yin, W., et al. (2016). FAP promotes immunosuppression by cancer-associated fibroblasts in the tumor microenvironment via STAT3-CCL2 signaling. Cancer Res. 76, 4124-4135. doi: 10.1158/0008-5472.CAN-15-2973

Yari, K., Rahimi, Z., Moradi, M. T., and Rahimi, Z. (2014). The MMP-2 -735 C allele is a risk factor for susceptibility to breast cancer. Asian Pac. J. Cancer Prev. 15, 6199-6203.

Yeung, T. L., Leung, C. S., Wong, K. K., Samimi, G., Thompson, M. S., Liu, J., et al. (2013). TGF-beta modulates ovarian cancer invasion by upregulating CAFderived versican in the tumor microenvironment. Cancer Res. 73, 5016-5028. doi: 10.1158/0008-5472.CAN-13-0023

Yoshimura, H., Michishita, M., Ohkusu-Tsukada, K., Matsuda, Y., Ishiwata, T., Naito, Z., et al. (2015). Cellular sources of tenascin-C in canine mammary carcinomas. Vet. Pathol. 52, 92-96. doi: 10.1177/0300985814522817

Yousef, E. M., Tahir, M. R., St-Pierre, Y., and Gaboury, L. A. (2014). MMP-9 expression varies according to molecular subtypes of breast cancer. BMC Cancer 14:609. doi: 10.1186/1471-2407-14-609

Yu, Y., Ding, Z., Jian, H., Shen, L., Zhu, L., and Lu, S. (2016). Prognostic value of MMP9 activity level in resected stage I B lung adenocarcinoma. Cancer Med. 5, 2323-2331. doi: 10.1002/cam4.821

Yu, Y., Xiao, C. H., Tan, L. D., Wang, Q. S., Li, X. Q., and Feng, Y. M. (2014). Cancer-associated fibroblasts induce epithelial-mesenchymal transition of breast cancer cells through paracrine TGF-beta signalling. Br. J. Cancer 110, 724-732. doi: 10.1038/bjc.2013.768

Zeisberg, E. M., Potenta, S., Xie, L., Zeisberg, M., and Kalluri, R. (2007a). Discovery of endothelial to mesenchymal transition as a source for carcinoma-associated fibroblasts. Cancer Res. 67, 10123-10128. doi: 10.1158/0008-5472.CAN-073127

Zeisberg, E. M., Tarnavski, O., Zeisberg, M., Dorfman, A. L., McMullen, J. R., Gustafsson, E., et al. (2007b). Endothelial-to-mesenchymal transition contributes to cardiac fibrosis. Nat. Med. 13, 952-961. doi: 10.1038/nm1613

Zhang, M., and Zhang, X. (2015). Association of MMP-2 expression and prognosis in osteosarcoma patients. Int. J. Clin. Exp. Pathol. 8, 14965-14970.

Zhang, X., Schonrogge, M., Eichberg, J., Wendt, E. H. U., Kumstel, S., Stenzel, J., et al. (2018). Blocking autophagy in cancer-associated fibroblasts supports chemotherapy of pancreatic cancer cells. Front. Oncol. 8:590. doi: 10.3389/fonc. 2018.00590

Zhang, Y., Shen, Y., Cao, B., Yan, A., and Ji, H. (2015). Elevated expression levels of androgen receptors and matrix metalloproteinase-2 and -9 in 30 cases of hepatocellular carcinoma compared with adjacent tissues as predictors of cancer invasion and staging. Exp. Ther. Med. 9, 905-908. doi: 10.3892/etm.2014.2150

Zhu, C. Q., Popova, S. N., Brown, E. R., Barsyte-Lovejoy, D., Navab, R., Shih, W., et al. (2007). Integrin alpha 11 regulates IGF2 expression in fibroblasts to enhance tumorigenicity of human non-small-cell lung cancer cells. Proc. Natl. Acad. Sci. U.S.A. 104, 11754-11759. doi: 10.1073/pnas.0703040104

Conflict of Interest Statement: The authors declare that the research was conducted in the absence of any commercial or financial relationships that could be construed as a potential conflict of interest.

Copyright (c) $2019 \mathrm{Liu}$, Zhou, Li, Andl and Zhang. This is an open-access article distributed under the terms of the Creative Commons Attribution License (CC BY). The use, distribution or reproduction in other forums is permitted, provided the original author(s) and the copyright owner(s) are credited and that the original publication in this journal is cited, in accordance with accepted academic practice. No use, distribution or reproduction is permitted which does not comply with these terms. 